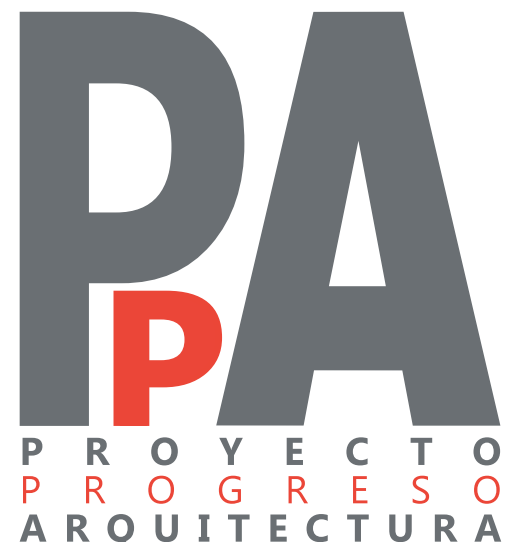

ARQUITECTURAS AMPLIADAS

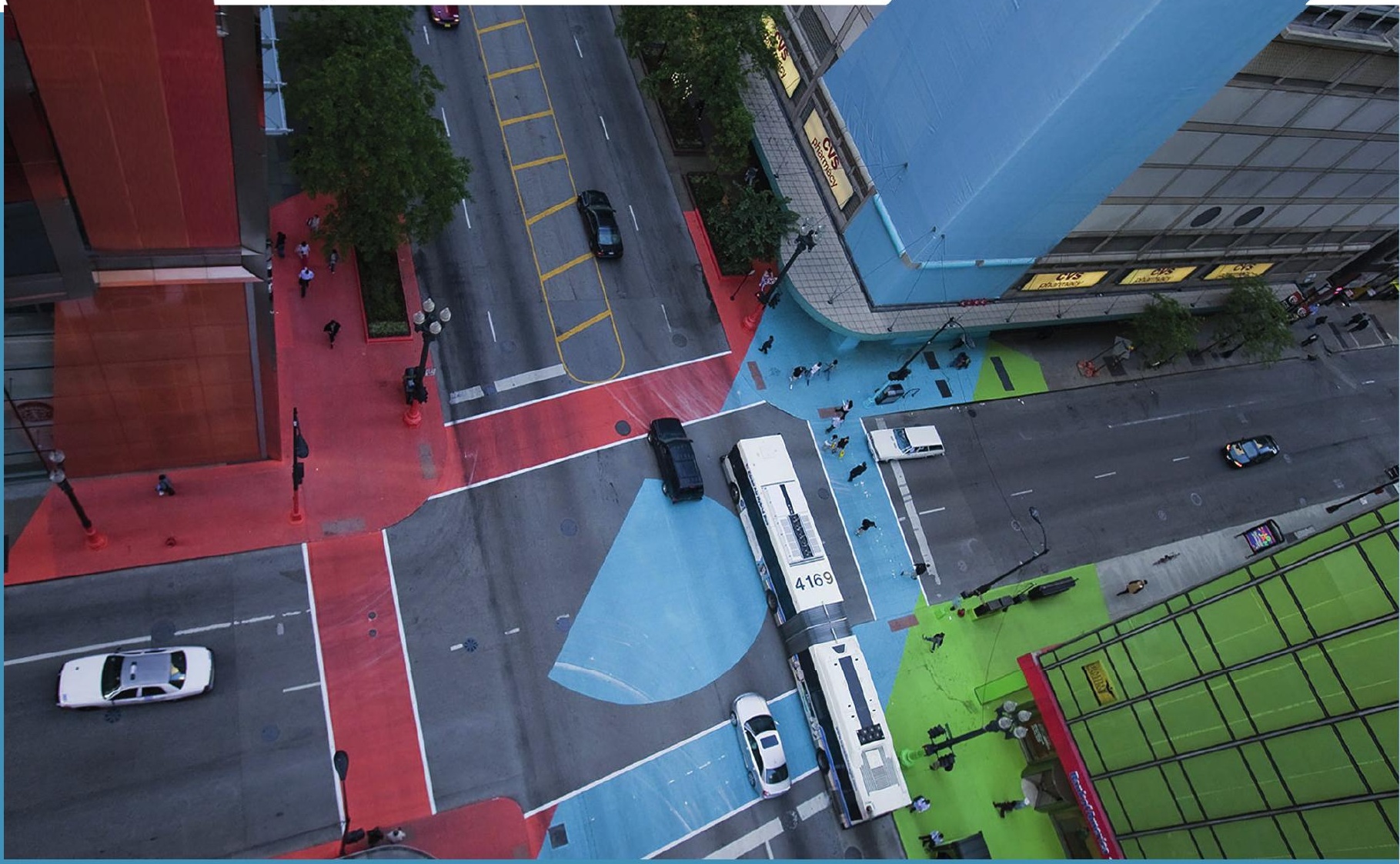




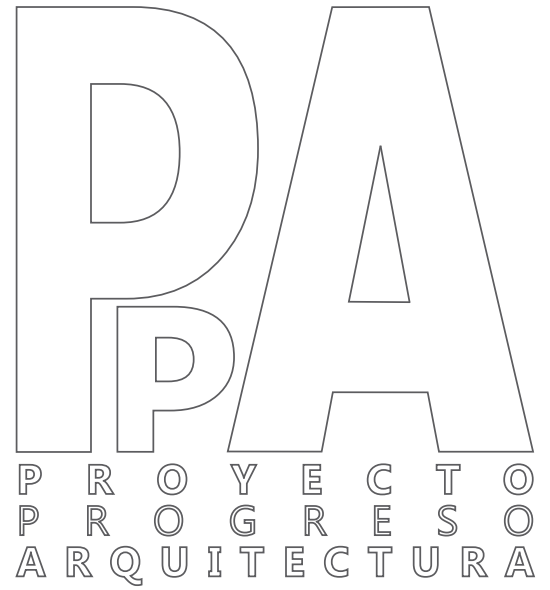

\section{ARQUITECTURAS AMPLIADA}

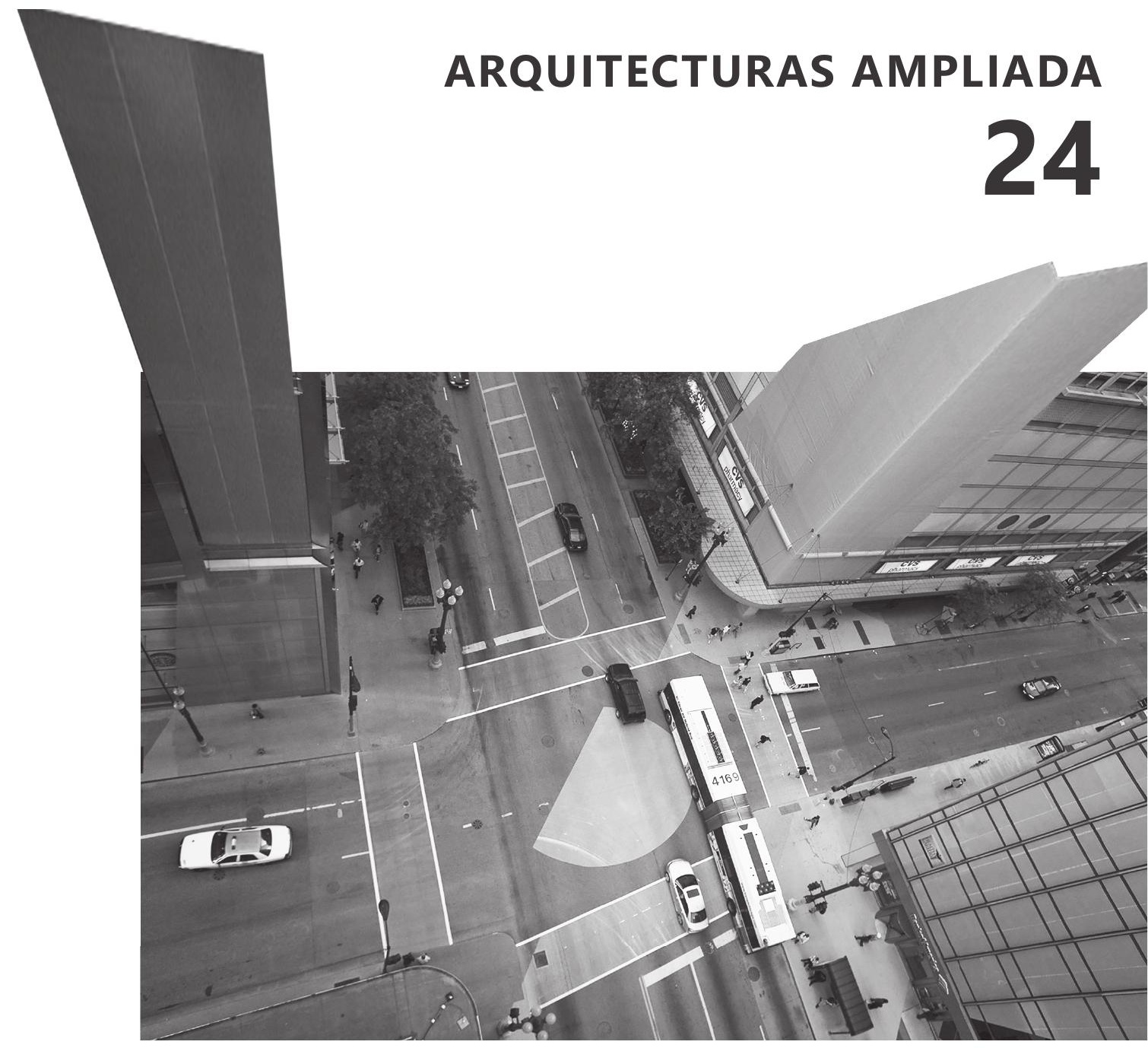

EDITORIAL UNIVERSIDAD DE SEVILLA AÑO 2019. ISSN 2171-6897 ISSNe 2173-1616 DOI: http://dx.doi.org/10.12795/ppa 


\section{REVISTA PROYECTO PROGRESO ARQUITECTURA}

N2/4

arquitecturas ampliadas
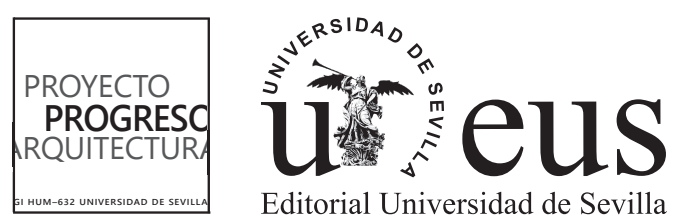


\section{arquitecturas ampliadas}

EDITA

Editorial Universidad de Sevilla. Sevilla

DIRECCIÓN CORRESPONDENCIA CIENTÍFICA

E.T.S. de Arquitectura. Avda Reina Mercedes, nº $241012-$

Sevilla.

Amadeo Ramos Carranza, Dpto. Proyectos Arquitectónicos.

e-mail: revistappa.direccion@gmail.com

\section{EDICIÓN ON-LINE}

Portal informático https://revistascientificas.us.es/index.php/ppa Portal informático Grupo de Investigación HUM-632

http://www. proyectoprogresoarquitectura.com

Portal informático Editorial Universidad de Sevilla http://www. editorial.us.es/

(c) EDITORIAL UNIVERSIDAD DE SEVILLA, 2019.

Calle Porvenir, 27. 41013 SEVILLA. Tfs. 954487447 / 954487451

Fax 954487443. [eus4@us.es] [http://www.editorial.us.es]

(c) TEXTOS: SUS AUTORES,

(C) IMÁGENES: SUS AUTORES Y/O INSTITUCIONES

DISEÑO PORTADA:

Rosa María Añón Abajas - Amadeo Ramos Carranza

En base a la fotografía: (C) Jessica Stockholder, cortesía de la artista y de Mitchell-Innes \& Nash, Nueva York

\section{DISEÑO PLANTILLA PORTADA-CONTRAPORTADA}

Miguel Ángel de la Cova Morillo-Velarde

DISEÑO PLANTILLA MAQUETACIÓN

Maripi Rodríguez

MAQUETACIÓN

Referencias Cruzadas

CORRECCION ORTOTIPOGRÁFICA

José Antonio Duarte

ISSN (ed. impresa): 2171-6897

ISSN-e (ed. electrónica): 2173-1616

DOI: http://dx.doi.org/10.12795/ppa

DEPÓSITO LEGAL: SE-2773-2010

PERIOCIDAD DE LA REVISTA: MAYO Y NOVIEMBRE

IMPRIME: PODIPRINT

Reservados todos los derechos. Ni la totalidad ni parte de esta revista puede reproducirse o transmitirse por ningún procedimiento electrónico o mecánico, incluyendo fotocopia, grabación magnética o cualquier almacenamiento de información y sistema de recuperación, sin permiso escrito de la Editorial Universidad de Sevilla.

Las opiniones y los criterios vertidos por los autores en los artículos firmados son responsabilidad exclusiva de los mismos. 


\section{DIRECCIÓN}

Dr. Amadeo Ramos Carranza. Escuela Técnica Superior de Arquitectura. Universidad de Sevilla. España

\section{SECRETARÍA}

Dra. Rosa María Añón Abajas. Escuela Técnica Superior de Arquitectura. Universidad de Sevilla. España

\section{EQUIPO EDITORIAL \\ Edición:}

Dr. Amadeo Ramos Carranza. Escuela Técnica Superior de Arquitectura. Universidad de Sevilla. España.

Dra. Rosa María Añón Abajas. Escuela Técnica Superior de Arquitectura. Universidad de Sevilla. España.

Dr. Francisco Javier Montero Fernández. Escuela Técnica Superior de Arquitectura. Universidad de Sevilla. España.

Dra. Esther Mayoral Campa. Escuela Técnica Superior de Arquitectura. Universidad de Sevilla. España.

Dr. Miguel Ángel de la Cova Morillo-Velarde. Escuela Técnica Superior de Arquitectura. Universidad de Sevilla. España.

Dr. Germán López Mena. Escuela Técnica Superior de Arquitectura. Universidad de Sevilla. España.

Dra. Gloria Rivero Lamela. Escuela Técnica Superior de Arquitectura. Universidad de Sevilla. España.

Juan José López de la Cruz. Escuela Técnica Superior de Arquitectura. Universidad de Sevilla. España.

Guillermo Pavón Torrejón. Escuela Técnica Superior de Arquitectura. Universidad de Sevilla. España.

Externos edición (asesores):

Dr. José Altés Bustelo. Escuela Técnica Superior de Arquitectura. Universidad de Valladolid. España.

Dr. Carlos Arturo Bell Lemus. Facultad de Arquitectura. Universidad del Atlántico. Colombia.

Dr. José de Coca Leicher. Escuela Técnica Superior de Arquitectura. Universidad Politécnica de Madrid. España. Dra. Patricia de Diego Ruiz. Escuela Técnica Supeiror de Arquitectura y Geodesia. Universidad Alcalá de Heranes. España.

Dr. Alfonso del Pozo y Barajas. Escuela Técnica Superior de Arquitectura. Universidad de Sevilla. España.

Dr. Jaume J. Ferrer Fores. Escola Tècnica Superior

d'Arquitectura de Barcelona. Universitat Politècnica de Catalunya. España.

Dra. Laura MArtínez Guereñu. El School of Architecture \& Design, IE University, Madrid; Segovia. España.

Dra. Clara Mejía Vallejo. Escuela Técnica Superior de Arquitectura. Universidad Politécnica de Valencia. España.

Dra. Luz Paz Agras. Escuela Técnica Superior de Arquitectura. Universidade da Coruña. España.

Dra. Marta Sequeira. CIAUD, Faculdade de Arquitectura da Universidade de Lisboa, Portugal.

\section{SECRETARÍA TÉCNICA}

Dra. Gloria Rivero Lamela. Escuela Técnica Superior de Arquitectura. Universidad de Sevilla. España.

\section{EDITORA Y COORDINACION CONTENIDOS CIENTÍFICOS DEL NÚMERO}

Dra. Rosa María Añón Abajas. Escuela Técnica Superior de Arquitectura. Universidad de Sevilla. España.

\section{COMITÉ CIÉNTIFICO}

Dr. Carlo Azteni. DICAAR. Dipartimento di Ingegneria Civile, Ambientale e Architettura. University Of Cagliari. Italia.

Dra. Maristella Casciato. GETTY Research Institute, GETTY, Los Angeles. Estados Unidos.

Dra. Anne Marie Châtelet. École Nationale Supérieure D'Architecture de Strasbourg (ENSAS). Francia.

Dr. Jean Louis Cohen. Institute of Fine Arts, New York University. Estados Unidos.

Dra. Josefina González Cubero. Escuela Técnica Superior de Arquitectura. Universidad de Valladolid. España.

Dr. José Manuel López Peláez. Escuela Técnica Superior de Arquitectura. Universidad Politécnica de Madrid. España.

Dra. Maite Méndez Baiges. Departamento de Historia del Arte. Universidad de Málaga. España.

Dr. Dietrich C. Neumann. Brown University In Providence, Ri (John Nicholas Brown Center For Public Humanities And Cultural Heritage). Estados Unidos.

Dr. Víctor Pérez Escolano. Catedrático Historia, Teoría y Composición Arquitectónicas. Escuela Técnica Superior de Arquitectura. Universidad de Sevilla. España.

Dr. Jorge Torres Cueco. Catedrático Proyectos Arquitectónicos. Escuela Técnica Superior de Arquitectura. Universitat Politècnica de València. España.

Dr. ir. Frank van der Hoeven, TU DELFT. Architecture and the Built Environment, Netherlands

\section{CORRESPONSALES}

Pablo de Sola Montiel. The Berlage Centre for Advanced Studies in Architecture and Urban Design. Paises Bajos.

Dr. Plácido González Martínez. Tongji University Caup (College Of architectura \& Urban Planing). Shangai, China.

Patrícia Marins Farias. Faculdade de Arquitetura. Universidade Federal da Bahia. Brasil.

Dr. Daniel Movilla Vega. Umeå School of Architecture. Umeå University. Suecia.

Dr. Pablo Sendra Fernández. The Bartlett School of Planning. University College London. Inglaterra.

Alba Zarza Arribas. Centro de Estudos Arnaldo Araújo, Porto. Portugal.

Dra. María Elena Torres Pérez. Facultad de Arquitectura. Universidad Autónoma de Yucatán, Mérida. México.

\section{TEXTOS VIVOS}

Juan José López de la Cruz. Escuela Técnica Superior de Arquitectura. Universidad de Sevilla. España.

Dr. Francisco Javier Montero Fernández. Escuela Técnica Superior de Arquitectura. Universidad de Sevilla. España. Dra. Esther Mayoral Campa. Escuela Técnica Superior de Arquitectura. Universidad de Sevilla. España. 


\section{SERVICIOS DE INFORMACIÓN}

\section{CALIDAD EDITORIAL}

La Editorial Universidad de Sevilla cumple los criterios establecidos por la Comisión Nacional Evaluadora de la Actividad Investigadora para que lo publicado por el mismo sea reconocido como "de impacto" (Ministerio de Ciencia e Innovación, Resolución 18939 de 11 de noviembre de 2008 de la Presidencia de la CNEAI, Apéndice I, BOE n² 282, de 22.11.08).

La Editorial Universidad de Sevilla forma parte de la U.N.E. (Unión de Editoriales Universitarias Españolas) ajustándose al sistema de control de calidad que garantiza el prestigio e internacionalidad de sus publicaciones.

PUBLICATION QUALITY

The Editorial Universidad de Sevilla fulfils the criteria established by the National Commission for the Evaluation of Research Activity (CNEAI) so that its publications are recognised as "of impact" (Ministry of Science and Innovation, Resolution 18939 of 11 November 2008 on the Presidency of the CNEAl, Appendix I, BOE No 282, of 22.11.08).

The Editorial Universidad de Sevilla operates a quality control system which ensures the prestige and international nature of its publications, and is a member of the U.N.E. (Unión de Editoriales Universitarias Españolas-Union of Spanish University Publishers).

Los contenidos de la revista PROYECTO, PROGRESO, ARQUITECTURA aparecen en:

bases de datos: indexación
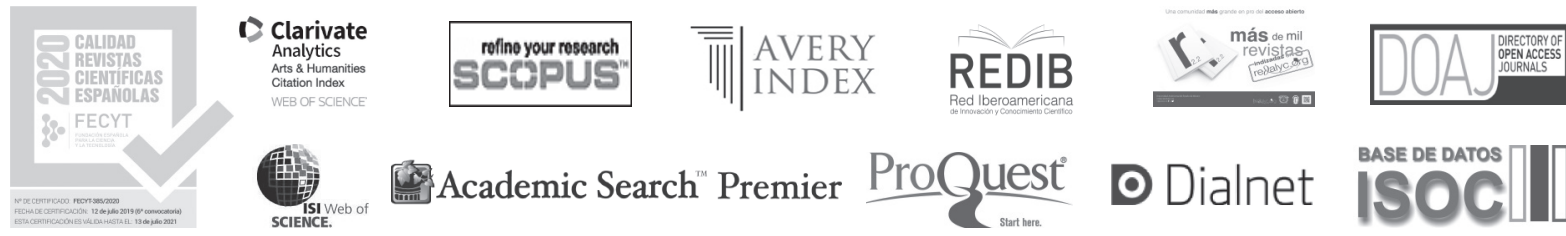

D Dialnet

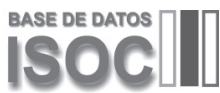

SELLO DE CALIDAD EDITORIAL FECYT 2019. RENOVADO 2020. (Cuartil C3)

WoS. Arts \& Humanities Citation Index

WoS. ESCl - Emerging Sources Citation Index

SCOPUS

AVERY. Avery Index to Architectural Periodicals

REBID. Red Iberoamericana de Innovación y Conocimiento Científico

REDALYC. Red de Revistas Científicas de América Latina y el Caribe, España y Portugal.

EBSCO. Fuente Académica Premier

EBSCO. Art Source

DOAJ, Directory of Open Access Journals

PROQUEST (Arts \& Humanities, full text)

DIALNET

ISOC (Producida por el CCHS del CSIC)

DRIJ. Directory of Research Journals Indexing

SJR (2019): 0.100, H index: 2

\section{catalogaciones: criterios de calidad}

RESH (Revistas Españolas de Ciencias Sociales y Humanidades).

Catálogos CNEAI (16 criterios de 19). ANECA (18 criterios de 21). LATINDEX (35 criterios sobre 36).

DICE (CCHS del CSIC, ANECA).

MIAR, Matriu d'Informació per a l'Avaluació de Revistes. IDCS 2018: 10,500. Campo ARQUITECTURA

CLASIFICACIÓN INTEGRADA DE REVISTAS CIENTÍFICAS (CIRC-CSIC): A

ERIHPLUS

SCIRUS, for Scientific Information.

ULRICH'S WEB, Global Serials Directory.

ACTUALIDAD IBEROAMERICANA.

\section{catálogos on-line bibliotecas notables de arquitectura:}

CLIO. Catálogo on-line. Columbia University. New York

HOLLIS. Catálogo on-line. Harvard University. Cambridge. MA

SBD. Sistema Bibliotecario e Documentale. Instituto Universitario di Architettura di Venezia

OPAC. Servizi Bibliotecari di Ateneo. Biblioteca Centrale. Politecnico di Milano

COPAC. Catálogo colectivo (Reino Unido)

SUDOC. Catálogo colectivo (Francia)

ZBD. Catálogo colectivo (Alemania)

REBIUN. Catálogo colectivo (España)

OCLC. WorldCat (Mundial) 
EVALUACIÓN EXTERNA POR PARES Y ANÓNIMA.

El Consejo Editorial remitirá el artículo a dos expertos revisores anónimos dentro del campo específico de investigación y crítica de arquitectura, según el modelo doble ciego.

El director de la revista comunicará a los autores el resultado motivado de la evaluación por correo electrónico, en la dirección que éstos hayan utilizado para enviar el artículo. El director comunicará al autor principal el resultado de la revisión (publicación sin cambios; publicación con correcciones menores; publicación con correcciones importantes; no aconsejable para su publicación), así como las observaciones y comentarios de los revisores.

Si el manuscrito ha sido aceptado con modificaciones, los autores deberán reenviar una nueva versión del artículo, atendiendo a las demandas y sugerencias de los evaluadores externos. Los artículos con correcciones importantes serán remitidos al Consejo Asesor para verificar la validez de las modificaciones efectuadas por el autor. Los autores pueden aportar también una carta al Consejo Editorial en la que indicarán el contenido de las modificaciones del artículo. Los artículos con correcciones importantes serán remitidos al Consejo Asesor para verificar la validez de las modificaciones efectuadas por el autor.

\section{DECLARACIÓN ÉTICA SOBRE PUBLICACIÓN Y MALAS PRÁCTICAS}

La revista PROYECTO, PROGRESO, ARQUITECTURA (PPA) está comprometida con la comunidad académica en garantizar la ética y calidad de los artículos publicados. Nuestra revista tiene como referencia el Código de Conducta y Buenas Prácticas que, para editores de revistas científicas, define el COMITÉ DE ÉTICA DE PUBLICACIONES (COPE).

Así nuestra revista garantiza la adecuada respuesta a las necesidades de los lectores y autores, asegurando la calidad de lo publicado, protegiendo y respetando el contenido de los artículos y la integridad de los mismo. El Consejo Editorial se compromete a publicar las correcciones, aclaraciones, retracciones y disculpas cuando sea preciso.

En cumplimiento de estas buenas prácticas, la revista PPA tiene publicado el sistema de arbitraje que sigue para la selección de artículos así como los criterios de evaluación que deben aplicar los evaluadores externos -anónimos y por pares, ajenos al Consejo Editorial-. La revista PPA mantiene actualizados estos criterios, basados exclusivamente en la relevancia científica del artículo, originalidad, claridad y pertinencia del trabajo presentado.

Nuestra revista garantiza en todo momento la condifencialidad del proceso de evaluación: el anonimato de los evaluadores y de los autores; el contenido evaluado; los informes razonados emitidos por los evaluadores y cualquier otra comunicación emitida por los consejos Editorial, Asesor y Científico si así procediese.

Igualmente quedan afectados de la máxima confidencialidad las posibles aclaraciones, reclamaciones o quejas que un autor desee remitir a los comités de la revista o a los evaluadores del artículo.

La revista PROYECTO, PROGRESO, ARQUITECTURA (PPA) declara su compromiso por el respeto e integridad de los trabajos ya publicados. Por esta razón, el plagio está estrictamente prohibido y los textos que se identifiquen como plagio o su contenido sea fraudulento, serán eliminados o no publicados por la revista PPA. La revista actuará en estos casos con la mayor celeridad posible. Al aceptar los términos y acuerdos expresados por nuestra revista, los autores han de garantizar que el artículo y los materiales asociados a él son originales o no infringen derechos de autor. También los autores tienen que justificar que, en caso de una autoría compartida, hubo un consenso pleno de todos los autores afectados y que no ha sido presentado ni publicado con anterioridad en otro medio de difusión.

\section{EXTERNAL ANONYMOUS PEER REVIEW.}

Editorial Board will be sent to two anonymous experts, within the specific field of architectural investigation and critique, for a double blind review.

The Director of the journal will communicate the result of the reviewers evaluations to the authors by electronic mail, to the address used to send the article. The Director will communicate the result of the review (publication without changes; publication with minor corrections; publication with significant corrections; its publication is not advisable), as well as the observations and comments of the reviewers, to the main author.

If the manuscript has been accepted with modifications, the authors will have to resubmit a new version of the article, addressing the requirements and suggestions of the external reviewers. The articles with corrections will be sent to Advisory Board for verification of the validity of the modifications made by the author. The authors can also send a letter to the Editorial Board, in which they will indicate the content of the modifications of the article.

\section{ETHICS STATEMENT ON PUBLICATION AND BAD PRACTICES} PROYECTO, PROGRESO ARQUITECTURA (PPA) makes a commitment to the academic community by ensuring the ethics and quality of its published articles. As a benchmark, our journal uses the Code of Conduct and Good Practices which, for scientific journals, is defined for editors by the PUBLICATION ETHICS COMMITTEE (COPE).

Our journal thereby guarantees an appropriate response to the needs of readers and authors, ensuring the quality of the published work, protecting and respecting the content and integrity of the articles. The Editorial Board will publish corrections, clarifications, retractions and apologies when necessary.

In compliance with these best practices, PPA has published the arbitration system that is followed for the selection of articles as well as the evaluation criteria to be applied by the anonymous, external peer-reviewers. PPA keeps these criteria current, based solely on the scientific importance, the originality, clarity and relevance of the presented article.

Our journal guarantees the confidentiality of the evaluation process at all times: the anonymity of the reviewers and authors; the reviewed content; the reasoned report issued by the reviewers and any other communication issued by the editorial, advisory and scientific boards as required.

Equally, the strictest confidentiality applies to possible clarifications, claims or complaints that an author may wish to refer to the journal's committees or the article reviewers.

PROYECTO, PROGRESO ARQUITECTURA (PPA) declares its commitment to the respect and integrity of work already published. For this reason, plagiarism is strictly prohibited and texts that are identified as being plagiarized, or having fraudulent content, will be eliminated or not published in PPA. The journal will act as quickly as possible in such cases. In accepting the terms and conditions expressed by our journal, authors must guarantee that the article and the materials associated with it are original and do not infringe copyright. The authors will also have to warrant that, in the case of joint authorship, there has been full consensus of all authors concerned and that the article has not been submitted to, or previously published in, any other media. 
EVALUADORES EXTERNOS (publicación cada cuatro números, dos años). NÚMEROS 21 a 24 (incluidos)

Álvarez Álvarez, Darío. Catedrático de Universidad / Departamento de Teoría de la Arquitectura y Proyectos Arquitectónicos / ETS Arquitectura / Universidad de Valladolid / España.

Arrieta Berdasco, Valentín. Doctor Arquitecto, Profesor Asociado / Departamento de Teoría de la Arquitectura y Proyectos Arquitectónicos / ETS Arquitectura / Universidad de Valladolid / España.

Bardí i Milá, Berta. Profesora Asociada doctora / / Departamento de Projectes Arquitectònics / ETS Arquitectura / Universitat Politècnica de Catalunya, Barcelona Tech / España.

Bergera Serrano, Iñaki. Titular de Universidad / Unidad Predepartamental de Arquitectura / Área Proyectos Arquitectónicos / El y Arquitectura / Universidad de Zaragoza / España.

Bobbink, Inge. Dr. ir. Architecture / Section of landscape architecture / TU Delft / Países Bajos.

Burriel Bielza, Luis. Profesor Titular / École Nationale Supérieure d'Architecture de Paris-Belleville / Francia

Calatrava Escobar, Juan. Catedrático de Universidad / Departamento de Construcciones Arquitectónicas / ETS Arquitectura / Universidad de Granada / España.

Castellanos Gómez, Raúl. Titular de Universidad / Departamento de Proyectos Arquitectónicos / ETS Arquitectura / Universidad Politécnica de Valencia / España.

Centellas Soler, Miguel. Titular de Universidad / Departamento de Arquitectura y Tecnología de la Edificación / ETS Arquitectura y Edificación / Universidad Politécnica de Cartagena / España.

Chías Navarro, Pilar. Catedrática de Universidad / Departamento de Arquitectura / ETS Arquitectura y Geodesia / Universidad de Alcalá de Henares / España.

de Diego Ruiz, Patricia. Doctora arquitecta, Profesora Asociada / Departamento de Arquitectura / ETS Arquitectura y Geodesia / Universidad de Alcalá de Henares / España.

de la Iglesia Salgado, Félix. Profesor Contratado Doctor / Departamento de Proyectos Arquitectónicos / ETS Arquitectura / Universidad de Sevilla / España.

de la O Cabrera, Manuel Rodrigo. Doctor Arquitecto, Profesor Asociado / Departamento de Composición Arquitectónica / ETS Arquitectura / Universidad Politécnica de Madrid / España.

Delgado Orusco, Eduardo. Profesor Ayudante Doctor / Departamento de Arquitectura. Área de Proyectos Arquitectónicos / Escuela de Ingeniería y Arquitectura / Universidad de Zaragoza / España.

Deltell Pastor, Juan. Titular de Universidad / Departamento de Proyectos Arquitectónicos / ETS Arquitectura / Universitat Politècnica de València / España.

Diañez Rubio, Pablo. Titular de Universidad / Departamento de Proyectos Arquitectónicos / ETS Arquitectura / Universidad de Sevilla / España.

Díaz Segura, Alfonso. Titular de Universidad / Proyectos, Teoría y Técnica del Diseño y la Arquitectura / ETS Arquitectura / Universidad CEU Cardenal Herrera, Valencia / España.

Domingo Calabuig, Débora. Titular de Universidad / Departamento de Proyectos Arquitectónicos / ETS Arquitectura / Universidad Politécnica de Valencia / España.

Fernández Fariña, Almudena. Profesora Contratada Doctora / Departamento de Pintura / Facultad de Bellas Artes / Universidad de Vigo / España.

Fernández-Trapa de Isasi, Justo. Catedrático de Universidad / Departamento de Proyectos Arquitectónicos / ETS Arquitectura / Universidad Politécnica de Madrid / España.

García Escudero, Daniel. Dr. Arquitecto, Profesor Lector / Departamento de Projectes Arquitectònics / ETS Arquitectura / Universitat Politècnica de Catalunya, Barcelona Tech / España.

González Cubero, Josefina. Titular de Universidad / Departamento de Teoría de la Arquitectura y Proyectos Arquitectónicos / ETS Arquitectura / Universidad de Valladolid / España.

González Fraile, Eduardo. Catedrático de Universidad / Departamento de Teoría de la Arquitectura y Proyectos Arquitectónicos / ETS Arquitectura / Universidad de Valladolid / España.

Gorostiza López, Jorge. Doctor Arquitecto. Cineasta / España.

Hernández Moreno, Silverio. Profesor investigador titular / Facultad de Arquitectura y Diseño / Universidad Autónoma del Estado de México / México.

Labarta Aizpún, Carlos. Titular de Universidad / Unidad Predepartamental de Arquitectura / Área Proyectos Arquitectónicos / Escuela de Ingeniería y Arquitectura / Universidad de Zaragoza / España.

Lizondo Sevilla, Laura. Titular de Universidad / Departamento de Proyectos Arquitectónicos / ETS Arquitectura / Universidad Politécnica de Valencia / España.

Llopis Verdú, Jorge. Catedrático de Universidad / Departamento de Expresión Gráfica Arquitectónica / ETS Arquitectura / Universidad Politécnica de Valencia / España.

López Bahut, Emma. Profesora Contratada Doctora / Departamento de Proyectos arquitectónicos, Urbanismo y Composición / ETS Arquitectura / Universidade da Coruña / España.

López Fernández, Andrés. Titular de Universidad / Departamento de Proyectos Arquitectónicos / ETS Arquitectura / Universidad de Sevilla / España.

Loren Méndez, Mar. Catedrática de Universidad / Departamento de Historia, Teoría y Composición Arquitectónica / ETS Arquitectura / Universidad de Sevilla / España.

Maino Ansaldo, Sandro. Doctor Arquitecto / Departamento Arquitectura / Universidad Técnica Federico Santa María / Chile.

Mària i Serrano, Magda. Profesora Contratada Doctor / Departamento de Projectes Arquitectònics / ETS Arquitectura del Vallès / Universitat Politècnica de Catalunya / España

Marson, Anna. Profesora Ordinario / Dipartimento di culture del progetto / Istituto Universitario di Architettura di Venezia / Università di Venezia / Italia.

Martínez Díaz, Ángel. Titular de Universidad / Departamento de Ideación Gráfica Arquitectónica / ETS Arquitectura / Universidad Politécnica de Madrid / España. 
Mejía Vallejo, Clara. Titular de Universidad / Departamento de Proyectos Arquitectónicos / ETS Arquitectura / Universidad Politécnica de Valencia / España.

Mercader Moyano, Pilar. Titular de Universidad / Departamento de Proyectos Arquitectónicos / ETS Arquitectura / Universidad de Sevilla / España.

Mercé Hospital, José María. Catedrático de Universidad / Departamento de Proyectos Arquitectónicos / ETS Arquitectura y Geodesia / Universidad Alcalá de Henares / España.

Merí de la Maza, Ricardo. Titular de Universidad / Departamento de Proyectos Arquitectónicos / ETS Arquitectura / Universidad Politécnica de Valencia / España.

Mestre Martínez, Nieves. Doctora arquitecta, Profesora Asociada / Departamento de Proyectos Arquitectónicos / ETS Arquitectura / Universidad Politécnica de Madrid / España.

Millán Gómez, Antonio. Catedrático de Universidad / Departamento d’Expressió Gràfica Arquitectònica I / ETS Arquitectura del Vallès / Universitat Politècnica de Catalunya / España.

Moreno Pérez, José Ramón. Titular de Universidad / Dpto. Historia, Teoría y Composición Arquitectónica / ETS Arquitectura / Universidad de Sevilla / España.

Nijhuis, Steffen. Associate Professor. Head of Landscape Architecture Research / Section of Landscape Architecture / Department of Urbanism / Faculty of Architecture and the Built Environment / TU Delft / Países Bajos.

Ojeda Rivera, Juan Francisco. Catedrático de Universidad / Departamento de Geografía, Historia y Filosofía / Universidad Pablo de Olavide, Sevilla / España.

Paz-Agras, Luz. Profesora Ayudante doctor / Departamento de Proyectos Arquitectónicos, Urbanismo y Composición. Área de Composición Arquitectónica / ETS Arquitectura / Universidad de A Coruña / España

Pérez Moreno, Lucía C. Titular de Universidad / Departamento de Arquitectura. Área de Composición Arquitectónica / Escuela de Ingeniería y Arquitectura / Universidad de Zaragoza / España.

Pina Lupiañez, Rafael. Profesor Contratado Doctor / Departamento de Proyectos Arquitectónicos / ETS Arquitectura / Universidad Politécnica de Madrid / España

Oliverira do Nascimento, Francisco. Professor Auxiliar / Faculdade de Arquitetura / Universidade de Lisboa / Portugal.

Rovira Llobera, Teresa. Titular de Universidad / Departamento de Projectes Arquitectònics / ETS Arquitectura / Universitat Politècnica de Catalunya, Barcelona Tech / España.

Ruiz Rosa, José Antonio. Catedrático de Universidad / Departamento de Expresión Gráfica Arquitectónica / ETS Arquitectura / Universidad de Sevilla. / España.

Sabaté Bel, Joaquín. Catedrático de Universidad / Departamento de Urbanismo y Ordenación del Territorio / ETS Arquitectura / Universitat Politècnica de Catalunya, Barcelona Tech / España

Sainz Gutiérrez Victoriano. Titular de Universidad / Departamento de Urbanismo y Ordenación del Territorio / ETS Arquitectura / Universidad de Sevilla / España

Sánchez Lampreave, Ricardo. Profesor Titular / Área de Composición Arquitectónica / Escuela de Ingeniería y Arquitectura / Universidad de Zaragoza / España.

Sambricio R. Echegaray, Carlos. Catedrático de Universidad / Departamento de Composición Arquitectónica / ETS Arquitectura / Universidad Politécnica de Madrid / España. / España.

Santamarina-Macho, Carlos. España. Doctor Arquitecto, Profesor Asociado / Departamento de Teoría de la Arquitectura y Proyectos Arquitectónicos / ETS Arquitectura / Universidad de Valladolid / España

Senra Fernández-Miranda, Ignacio. Doctor Arquitecto, Profesor Asociado / Departamento de Proyectos Arquitectónicos / ETS Arquitectura / Universidad Politécnica de Madrid / España.

Sentieri Omarrementeria, Carla. Titular de Universidad / Departamento de Proyectos Arquitectónicos / ETS Arquitectura / Universidad Politécnica de Valencia / España.

Sequeira Marta. Professora doctora / ISCTE - Instituto Universitário de Lisboa/ Universidade Autónoma de Lisboa / CIAUD - Faculdade de Arquitectura da Universidade de Lisboa / Portugal.

Sola Alonso, José Ramón. España. Profesor Contratado Doctor / Departamento de Teoría de la Arquitectura y Proyectos Arquitectónicos / ETS Arquitectura / Universidad de Valladolid / España.

Trillo Martínez, Valentín. Doctor arquitecto Profesor Asociado / Departamento de Proyectos Arquitectónicos / ETS Arquitectura / Universidad de Sevilla / España.

Villalobos Alonso, Daniel. Titular de Universidad / Departamento de Teoría de la Arquitectura y Proyectos Arquitectónicos / ETS Arquitectura / Universidad de Valladolid / España.

Verde Zein, Ruth. Doctora arquitecto e investigadora / Facultad de Arquitectura y Urbanismo / Universidad Presbiteriana Mackenzie. São Paulo / Brasil.

\section{ESTADÍSTICAS PUBLICACIÓN (publicación cada cuatro números, dos años). NÚMEROS 1 a 20 (incluidos)}

Total artículos recibidos: 546

Total artículos publicados: 199 (36,45\%)

Total artículos rechazados: $347(63,55 \%)$

Total artículos publicados de autores pertenecientes a los diferentes consejos o comités organizadores de la revista y Grupo de Investigación "proyecto, progreso, arquitectura"(endogamia): 20 (10,05\%)

Total artículos publicados de autores pertenecientes a la Universidad de Sevilla: 53 (26,63\%)

Total artículos publicados de autores externos a los diferentes consejos o comités organizadores de la revista y Grupo de Investigación

"proyecto, progreso, arquitectura": 179 (89,95\%)

Total artículos publicados de autores extranjeros: 17 (8,54\%) 


\section{arquitecturas ampliadas}

índice

editorial

DESPEJAR LA ARQUITECTURA, LIBERAR EL ESPACIO Y AMPLIAR CONCEPTOS / UNCLUTTER ARCHITECTURE, FREE UP SPACE AND EXPAND CONCEPTS

Rosa María Añón-Abajas - (DOI: http://dx.doi.org/10.12795/ppa.2021.i24.10)

entre líneas

PAISAJES ARQUITECTÓNICOS Y MEMORIAS DE LA CIUDAD / ARCHITECTURAL LANDSCAPES AND MEMORIES OF THE CITY

Darío Álvarez Álvarez - (D0l: http://dx.doi.org/10.12795/ppa.2021.i24.01)

artículos

LINAZASORO EN REIMS. EL ESPACIO PÚBLICO COMO MEMORIA DEL LUGAR / LINAZASORO IN REIMS. THE PUBLIC SPACE AS THE MEMORY OF THE PLACE

Victoriano Sainz Gutiérrez - (DOl: http://dx.doi.org/10.12795/ppa.2021.i24.02)

EDITAR VS. CONSTRUIR: UNA ECOLOGÍA DE LO INVISIBLE. AMPLIFICAR LA COMPRENSIÓN DE LAS TÉCNICAS DE PROYECTO / EDITING VS. BUILDING: AN ECOLOGY OF THE INVISIBLE. AMPLIFYING THE UNDERSTANDING OF ARCHITECTURAL DESIGN TECHNIQUES

Paula Victoria Álvarez Benítez - (DOI: http://dx.doi.org/10.12795/ppa.2021.i24.03)

CUANDO LA PINTURA AMPLÍA LA ARQUITECTURA: INTERVENCIONES REALIZADAS EN EL ESPACIO PÚBLICO / WHEN PAINTING ENHANCES ARCHITECTURE: INTERVENTIONS IN A PUBLIC SETTING Aurora Alcaide-Ramírez; Ana Ruiz-Abellón - (D0l: http://dx.doi.org/10.12795/ppa.2021.i24.04)

UN EDIFICIO INVISIBLE. NUEVO AULARIO DE LA FACULTAD DE DERECHO DE LA UNIVERSIDAD DE ZARAGOZA (1983-1996) / AN INVISIBLE BUILDING. NEW LECTURE ROOM BUILDING OF THE FACULTY OF LAW OF THE UNIVERSITY OF ZARAGOZA (1983-1996)

Luis Miguel Lus-Arana; Lucía Carmen Pérez-Moreno - (D0l: http://dx.doi.org/10.12795/ppa.2021.i24.05)

ARQUITECTURAS AMPLIADAS. EL PABELLÓN DE EXPOSICIONES EN LA CASA DE CAMPO DE MADRID) / EXPANDED ARCHITECTURES. THE EXHIBITION PAVILION AT THE CASA DE CAMPO IN MADRID José de Coca Leicher - (DOI: http://dx.doi.org/10.12795/ppa.2021.i24.06)

reseña bibliográfica TEXTOS VIVOS

RAFAEL MONEO VALLÉS: LA VIDA DE LOS EDIFICIOS. LA MEZQUITA DE CÓRDOBA, LA LONJA DE SEVILLA Y UN CARMEN EN GRANADA

Víctor Pérez Escolano - (DOl: http://dx.doi.org/10.12795/ppa.2021.i24.07)

FRANCISCO DE GRACIA: CONSTRUIR EN LO CONSTRUIDO. LA ARQUITECTURA COMO MODIFICACIÓN

Pablo Diañez Rubio - (DOl: http://dx.doi.org/10.12795/ppa.2020.i24.08)

FRÉDÉRIC DRUOT, ANNE LACATON \& JEAN-PHILIPPE VASSAL PLUS: LA VIVIENDA COLECTIVA. TERRITORIO DE EXCEPCIÓN

Javier Terrados Cepeda - (DOI: http://dx.doi.org/10.12795/ppa.2021.i24.09) 


\title{
CUANDO LA PINTURA AMPLÍA LA ARQUITECTURA: INTERVENCIONES REALIZADAS EN EL ESPACIO PÚBLICO
}

\author{
WHEN PAINTING ENHANCES ARCHITECTURE: INTERVENTIONS IN A PUBLIC SETTING
}

Aurora Alcaide-Ramírez (https://orcid.org/0000-0001-5983-4200)

Ana Ruiz-Abellón (https://orcid.org/0000-0003-0885-0088)

RESUMEN El artículo analiza cuatro intervenciones pictóricas llevadas a cabo en el espacio público en las que la pintura actúa sobre la arquitectura, y a veces también sobre el pavimento y mobiliario urbano colindante, produciendo una resignificación del lugar. Los proyectos seleccionados, The museum of gravity, de Krijn de Koning; Color Jam, de Jessica Stockholder; Rockaway, de Katharina Grosse y la intervención en la empresa Flax Art \& Design de Heather Day, amplían la arquitectura intervenida posibilitando maneras diversas de experimentarla y percibirla. Para conseguir este fin, estas propuestas se materializan mediante composiciones abstractas (geométricas o gestuales-orgánicas) en las que el color detenta el máximo protagonismo, suponiendo un aporte adicional a la tonalidad original del entorno arquitectónico sobre el que se aplica, generalmente neutra y sin ninguna función específica. Entre las principales conclusiones del estudio destaca la utilización del color en todas las propuestas por su valor intrínseco y por su capacidad para transformar la percepción de las propiedades formales de la arquitectura intervenida; la unión de pasado y presente en dos de ellas, al actuar sobre edificios en ruinas o abandonados; la reversibilidad o carácter efímero de la mayoría de los proyectos; el diálogo con el entorno; la aproximación al urbanismo táctico en diferentes sentidos y el alejamiento de un planteamiento puramente decorativista.

PALABRAS CLAVE Pintura expandida; arte público; arquitectura; color; urbanismo táctico; abstracción.

SUMMARY This paper analyses four pictorial interventions carried out in a public setting; painting acts upon architecture in all of them, and occasionally over the road surface and nearby street furniture, achieving a re-signification of the place. The projects chosen (The Museum of Gravity by Krijn de Koning; Color Jam by Jessica Stockholder; Rockaway! by Katharina Grosse; and the intervention at Flax Art \& Design by Heather Day) enhance the intervened-upon architecture, and allow for different ways of experiencing and perceiving it. To that end, these proposals are shaped by means of abstract compositions (geometric or gestural-organic) in which colours play the main role, providing the original hues of the architectural environment over which they are applied -usually neutral and without any specific function- with their additional contribution. Among the main conclusions of the study, we should highlight the use of colour in every work for its intrinsic value and for its ability to change the perception of the formal properties of the intervened-upon architecture; the joining of past and present in two of them because of acting on dilapidated or abandoned buildings; the reversibility or ephemeral nature of most projects; the dialogue with the environment; an approach close to tactical urbanism in different ways, and keeping purely decorative approaches at a great distance.

KEYWORDS Expanded-field painting; public art; architecture; colour; tactical urbanism; abstraction 


\section{INTRODUCCIÓN}

A lo largo del siglo XX, especialmente a partir de los años sesenta, se llevan a cabo en numerosas ciudades intervenciones pictóricas que tienden a modificar la fisonomía exterior de los edificios y del espacio público en general. Calificadas como pintura mural, graffiti, postgraffiti, pintura site, site specific, arte urbano/street art, arte público, arte contextual o pintura expandida, según los casos y en función de los autores ${ }^{1}$, estas prácticas artísticas no solo actúan a nivel estético sobre las urbes, sino que también pueden afectar a la percepción original de los volúmenes arquitectónicos, servir como canal al servicio de la expresión particular del artista creador o de la ciudadanía y sus reivindicaciones. Asimismo, pueden establecer un diálogo con el contexto social, cultural, económico y/o territorial $-y$ sus características formales-, modificar la experiencia emocional (psicogeográfica) ${ }^{2}$ de una determinada zona de la ciudad, haciendo las ciudades más habitables, así como señalizar un lugar concreto convirtiéndolo en hito para el viandante, pero también acercar el arte a la sociedad, demandando en ocasiones su participación en la génesis y desarrollo de la obra, etcétera. En definitiva, estas acciones pictóricas llevadas a cabo sobre el tejido urbano, tienden a ampliar sus significados y sentidos, posibilitando otras maneras de experimentar y aprehender la ciudad y sus elementos arquitectónicos.

1. Nos referimos, entre otros, a los siguientes autores: GARÍ, Joan. La conversación mural. Ensayo para una lectura del graffiti. Madrid: Fundesco, 1995; PEIRÓ LÓPEZ, Juan Bautista (2010). El muro como soporte en la pintura contemporánea: anotaciones marginales. En: Arte público hoy: nuevas vías de consideración e interpretación crítica. Actas del Congreso Internacional de Críticos de Arte. España: ACYLCA y AECA, 2009, pp. 159-167; FERNÁNDEZ FARIÑA, Almudena. Pintura site. Santiago de Compostela: Dardo, 2014; MADERUELO, Javier. La idea de espacio en el arte y la arquitectura contemporáneos 1960-1989. Madrid: Akal, 2008; ARDENNE, Paul. Arte contextual. Creación artística en medio urbano, en situación, de intervención, de participación. Murcia: CENDEAC, 2006; FERNÁNDEZ FARIÑA, Almudena. Lo que la pintura no es. La lógica de la negación como afirmación del campo expandido en la pintura. Pontevedra: Diputación de Pontevedra, 2009.

2. En el primer número de la revista Internationale Situationniste, la psicogeografía es definida como "el estudio de los efectos precisos del medio geográfico, acondicionado o no conscientemente, sobre el comportamiento afectivo de lo individuos". FERNÁNDEZ CONSUEGRA, Celia Balbina. Internacional Situacionista, movimiento precursor del performance art. En: Revista index.comunicació [en línea]. Madrid: Universidad Rey Juan Carlos, 2014, vol. 4, n. ${ }^{1}$, p. 135 [consulta: 10-09-2020]. E-ISSN 2174-1859. Disponible en:

https://journals.sfu.ca/indexcomunicacion/index.php/indexcomunicacion/article/view/128/146 
Dentro de estas prácticas artísticas, este artículo se centra en las desarrolladas en Europa y Norteamérica a partir del siglo XXI cuyo protagonista es el color, elemento del lenguaje plástico y visual que asume la función de mediador entre las disciplinas de la pintura y la arquitectura, en composiciones abstractas que se expanden por las paredes de los edificios y del pavimento y el mobiliario urbano, activando la arquitectura y/o los elementos de su entorno. Quedan, por tanto, fuera del ámbito de estudio las propuestas con un grado de iconicidad medio o alto en las que el motivo representado acapara el interés compositivo. Pero también aquellas que se ejecutan exclusivamente sobre un único paramento de un edificio. Las obras analizadas tienen como soporte la superficie de diversos elementos que forman parte del espacio público, generalmente urbano.

La aplicación de color a la arquitectura, bien mediante pigmentación o a través de los materiales utilizados, no es una práctica novedosa; son numerosos los arquitectos que en la actualidad emplean el color en sus proyectos de una manera intencionada, tal es el caso de Sauerbruch \& Hutton, EMBT arquitectes, Herzog \& De Meuron, William Alsop, Jean Nouvel o el estudio MVRDV. Y mucho antes que ellos, Theo van Doesburg, Le Corbusier, Bruno Taut o Gerrit Rietveld, entre otros, consideraban el color como un elemento esencial en sus diseños. Lo que no es tan común en el ámbito arquitectónico es la incorporación del color con posterioridad a la terminación del edificio. Este modo de proceder es más propio de artistas que trabajan en solitario, que, a pesar de estar formados algunos de ellos también en arquitectura, incorporan el color de una manera más libre y personal, llegando a veces incluso a ocultar completamente las características formales de las construcciones de base. Tampoco es frecuente que al idear el diseño cromático exterior de un edificio el arquitecto valore la posibilidad de inserción del color fuera de los límites estrictos de la construcción, como sí hacen los artistas objeto de análisis en esta investigación que, de este modo, resignifican no solo la edificación y su entorno, sino también las estrategias cromáticas seguidas en la concepción inicial de la construcción. Con respecto a estas, Juan Serra establece tres posibilidades: "[La utilización del] color para interferir en la percepción de las propiedades visuales de la forma (su geometría, dimensiones, peso visual o textura), el color para interferir en la descripción del objeto arquitectónico (tanto su composición como su función), y el color por su valor cromático intrínseco"3.

A lo largo del artículo se revisan las siguientes cuatro propuestas: The museum of gravity (2009), de Krijn de Koning, Color Jam (2012), de Jessica Stockholder, Rockaway (2016), de Katharina Grosse, y la intervención en la empresa Flax Art \& Design (2016), de Heather Day. Su elección se debe a que comparten, además de las características señaladas en los párrafos anteriores, las siguientes: todas aplican el color de manera plana y no matérica o con relieve, rasgo que presentan incluso aquellas intervenciones en donde se trabaja con un acabado gestual u orgánico -las dos últimas mencionadas-. Cada una de ellas responde a un estilo pictórico diferente y enfoca la intervención in situ en el espacio público de una forma distinta, ofreciendo perspectivas diversas de este fenómeno. Asimismo, aunque ninguna de las cuatro está concebida desde el punto de vista del urbanismo táctico (al menos, esta no es la intención de sus creadores) $)^{4}$, presentan algunos rasgos que las hacen aproximarse a esta tendencia en diferentes sentidos y con varios grados de intensidad. Por último, todas las intervenciones objeto de estudio destacan por su alto valor estético, pero sin caer en el decorativismo colorista intrascendente (y no exento de cierta polémica cuando se materializa en edificios patrimoniales), presente en numerosas de las acciones pictóricas llevadas a cabo en el espacio urbano en los últimos años. Sobre estas dos últimas cuestiones se problematizará en el apartado "Discusión y conclusiones". 
KRIJN DE KONING: THE MUSEUM OF GRAVITY (2009) El trabajo del artista Krijn de Koning (Ámsterdam, 1963) se encuentra en el límite entre el arte y la arquitectura debido a que construye grandes estructuras con madera y yeso que después recubre con una brillante y homogénea capa de color. Se trata de habitáculos de aspecto minimalista que penetran en los interiores de edificaciones previas o que habitan sus exteriores, suelos, paredes y escaleras; posiblemente consecuencia directa de su doble formación: en artes visuales y en arquitectura ${ }^{5}$. Por lo tanto, crea arquitecturas dentro de otras ya existes, añadiendo una nueva capa temporal, de manera que el visitante experimenta el espacio como si fuera nuevo.

Un rasgo característico de De Koning es que integra su obra tanto en arquitecturas antiguas como en contemporáneas, preservando en todo momento el espacio original y siempre con un sentido reversible, gracias a los materiales que utiliza y a que no aplica la pintura directamente sobre el soporte arquitectónico, sino sobre sus construcciones modulares. Pero no solo son importantes para el artista el espacio y la forma, sino que el color es un elemento tan relevante como la estructura en sus proyectos.

Con sus instalaciones, De Koning aporta una experiencia sensorial del espacio y propone una nueva relación del hombre con el entorno construido. En The museum of gravity (2009) (véanse figuras 1,2 y 3) ${ }^{6}$, sus características estructuras de color se disponen de manera respetuosa, sobre y rodeando las ruinas de la abadía Ten Duinen (Koksijde, Bélgica), mostrando así nuevas posibilidades de usar e interpretar el lugar? ${ }^{7}$. Los diferentes contrastes cromáticos presentes en los paneles que integran la instalación del artista-claro-oscuro, cálido-frío, complementarios y cualitativo ${ }^{8}-$, aportan un contrapunto a los grises y tonos tierras con los que la pátina del tiempo ha recubierto a las piedras con las que fue construido este monasterio cisterciense. Se observa que la aplicación del color en este proyecto responde a las estrategias I y III definidas por Juan Serra9 ${ }^{9}$, pero también a la segunda, debido a que el color se adapta a la forma de las estructuras de madera construidas por el artista, aunque no de la arquitectura de la abadía.

También se aprecia un contraste visible entre materiales: el revestimiento liso y de tintas planas de las estructuras de De Koning frente a la rugosidad y heterogeneidad de la mampostería del edificio ${ }^{10}$. En relación con esta, hay que destacar que no toda es original, ya que gran parte de los restos de la abadía son fruto de una reconstrucción reciente. Este hecho capta el interés de De Koning y le motiva a reproducir con su obra la supuesta "realidad" de las ruinas para, en ese acto de redundancia o de hipérbole de lo artificial, desvelar la falacia arqueológica del lugar. En palabras del artista, sus estructuras coloreadas: "pretended to be 'real' architecture, in a situation of a 'real', lasting and 'serious' architecture that pretended to be 'fading' and declining"11. Al exponer al visitante a esta doble mentira: la de las arquitecturas ficticias de su intervención y la de los muros de piedra prefabricados, consigue generarle cierta inquietud y extrañeza, propiciando que se cuestione "[the] significance and 'truth' of the place as it was constructed and represented in reality"12.

5. SLEWE GALLERIE. Krijn de Koning - Bio [en línea]. Ámsterdam, sin fecha [consulta: 04-09-2020]. Disponible en: https://www.slewe.nl/artists/krijndekoning 6. Las imágenes a color de dichas figuras pueden verse en Designboom magazine. Disponible en: https://www.designboom.com/architecture/krijn-de-koningthe-museum-of-gravity/

7. KONING, Krijn de. Texts, Interviews, Articles. Krijn the Koning - Works. Sin fecha [consulta: 10-09-2020]. Disponible en: https://www.krijndekoning.nl/texts/ index.html

8. ITTEN, Johannes. El arte del color. Aproximación subjetiva y descripción objetiva del arte. Traducido al castellano por V. LAMíQUIZ. París: Bouret, 1975. Original publicado en 1961.

9. SERRA LLUCH, op. cit. supra, nota 3.

10. ARCHER, Nate. Krijn de Koning: The museum of gravity. Designboom magazine [en línea]. Milán, Italia, 6 octubre 2009 [consulta: 03-09-2020]. Disponible en: https://www.designboom.com/architecture/krijn-de-koning-the-museum-of-gravity/

11. Pretendían ser arquitectura 'real', en una situación de arquitectura 'real', 'duradera' y 'seria' que pretendía estar 'desvaneciéndose' y decayendo (traducción de las autoras). Comunicación personal con Krijn de Koning, 1 de febrero de 2021.

12. [El] significado y la "verdad" del lugar tal como fue construido y representado en la realidad (traducción de las autoras). Ídem. 

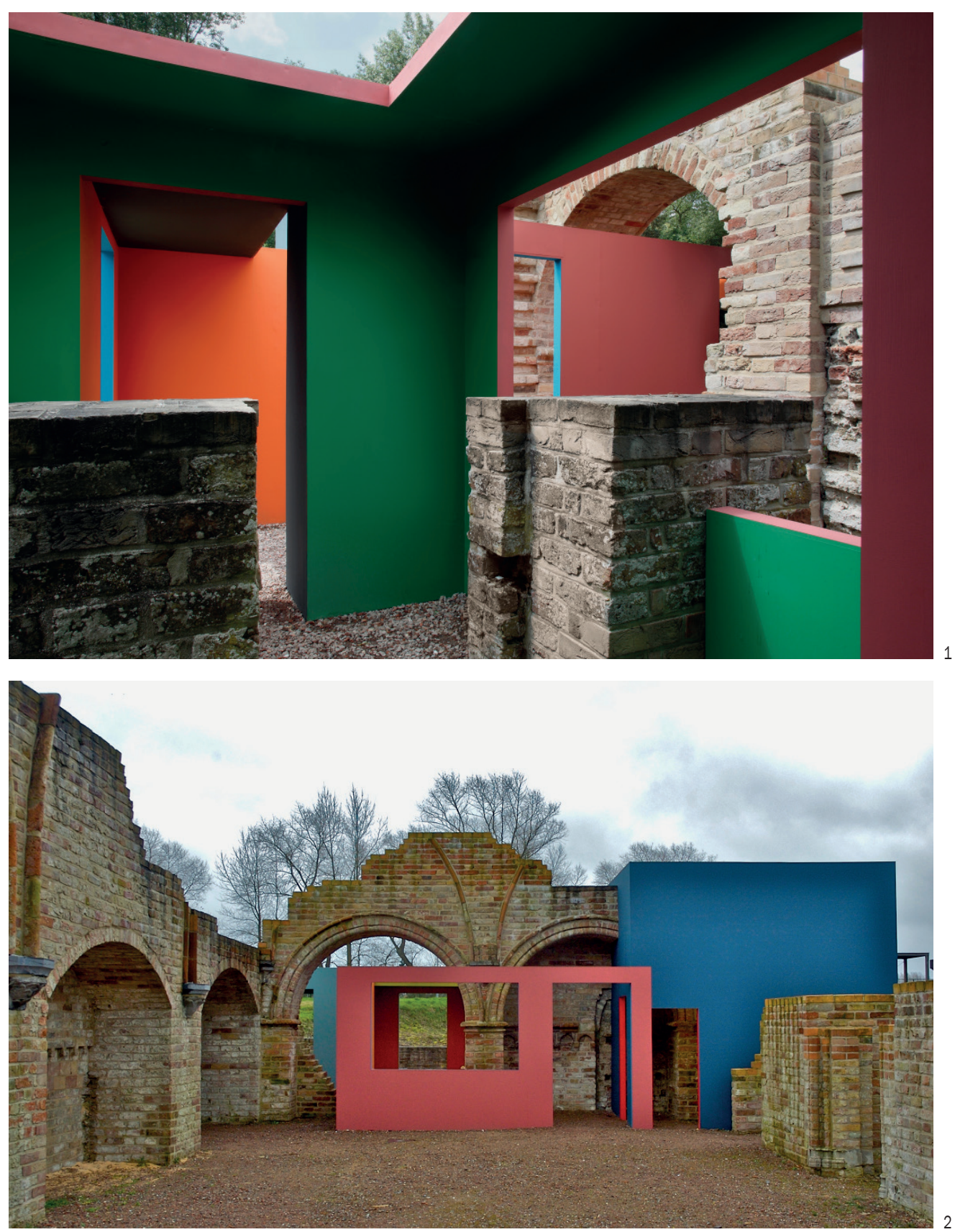

The museum of gravity formó parte de la Trienal de Arte Beaufort 03, que de marzo a octubre de 2009 acogió a una treintena de proyectos site specific desplegados por la costa de Bélgica, entablando diálogo con el mar, la herencia cultural y patrimonial, los lugareños y la historia local ${ }^{13}$. A los visitantes habituales de la abadía y del museo medieval situado junto a ella se sumaron los atraídos por la obra de De Koning, por lo que esta favoreció, en su opinión, que se le prestara una mayor atención al lugar, al cuestionarse "what and why that work was there"14.

13. Beaufort Triennale. Artmap. Sin fecha [consulta: 03-02-2021]. Disponible en: https://artmap.com/beauforttriennale/exhibition/beaufort032009-2009?print=do

14. Qué y por qué esa obra estaba allí (traducción de las autoras). Comunicación personal, op. cit. supra, nota 11. 
1, 2 y 3. Krijn de Koning, The museum of gravity, 2009. Imágenes de la intervención en Ten Duinen Abbey. Koksijde, Bélgica. @ Krijn de Koning, cortesía del artista.

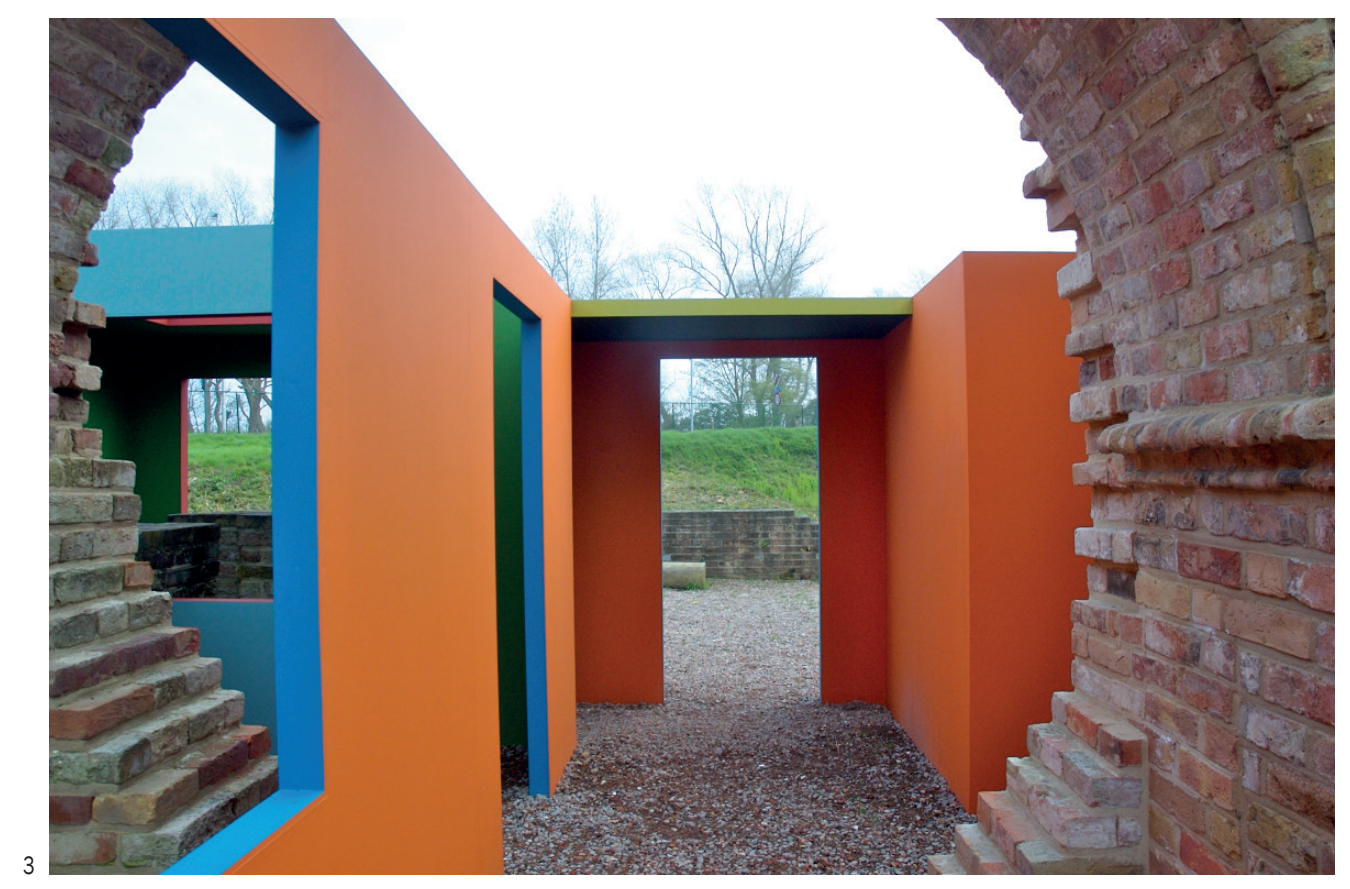

Asimismo, muchos de ellos, "simply enjoyed the work as some sort of a strange scenery in the situation"15, según apunta el artista.

\section{JESSICA STOCKHOLDER: COLOR JAM (2012)}

La artista y también profesora de Artes Visuales de la Universidad de Chicago, Jessica Stockholder (Seattle, 1959), se caracteriza por sus creaciones a partir de objetos ensamblados de distintos materiales y formas con los que interviene el espacio generando, en numerosas ocasiones, un diálogo con la arquitectura en proyectos site specific. Realiza piezas de pequeñas dimensiones, pero también obras monumentales que parten, en opinión de Jorge Kunitz, "de su afán por tomar conciencia del espacio en el que trabaja y de adherirse a él por medio de los materiales que utiliza"16.

Aunque algunos autores la ubican en el ámbito de la escultura, el protagonismo otorgado al color en sus instalaciones favorece que sus proyectos puedan ser calificados como pintura expandida, haciéndolos especialmente interesantes para esta investigación. La artista apunta al respecto: "Mis trabajos pueden entenderse como 'pinturas en el espacio'. Disfruto mucho orquestando la colisión de la experiencia estática de la pintura con la experiencia temporal de moverse por el espacio"17.

Trabaja con una paleta amplia y variada de colores contrastados, bien por luminosidad, saturación, temperatura o complementariedad ${ }^{18}$ que son propios de los

15. Simplemente disfrutaron el trabajo como una especie de escenario extraño en la situación (traducción de las autoras). Ídem.

16. KUNITZ, Jorge. Jessica Stockholder: "El color es el alma de mi trabajo". Tendencias del Mercado del Arte [en línea]. Enero 2012 [consulta: 11-09-2020]. Disponible en: http://www.tendenciasdelarte.com/jessica-stockholder-enero-2012/

17. Ibíd.

18. ITTEN, op. cit. supra, nota 8. 


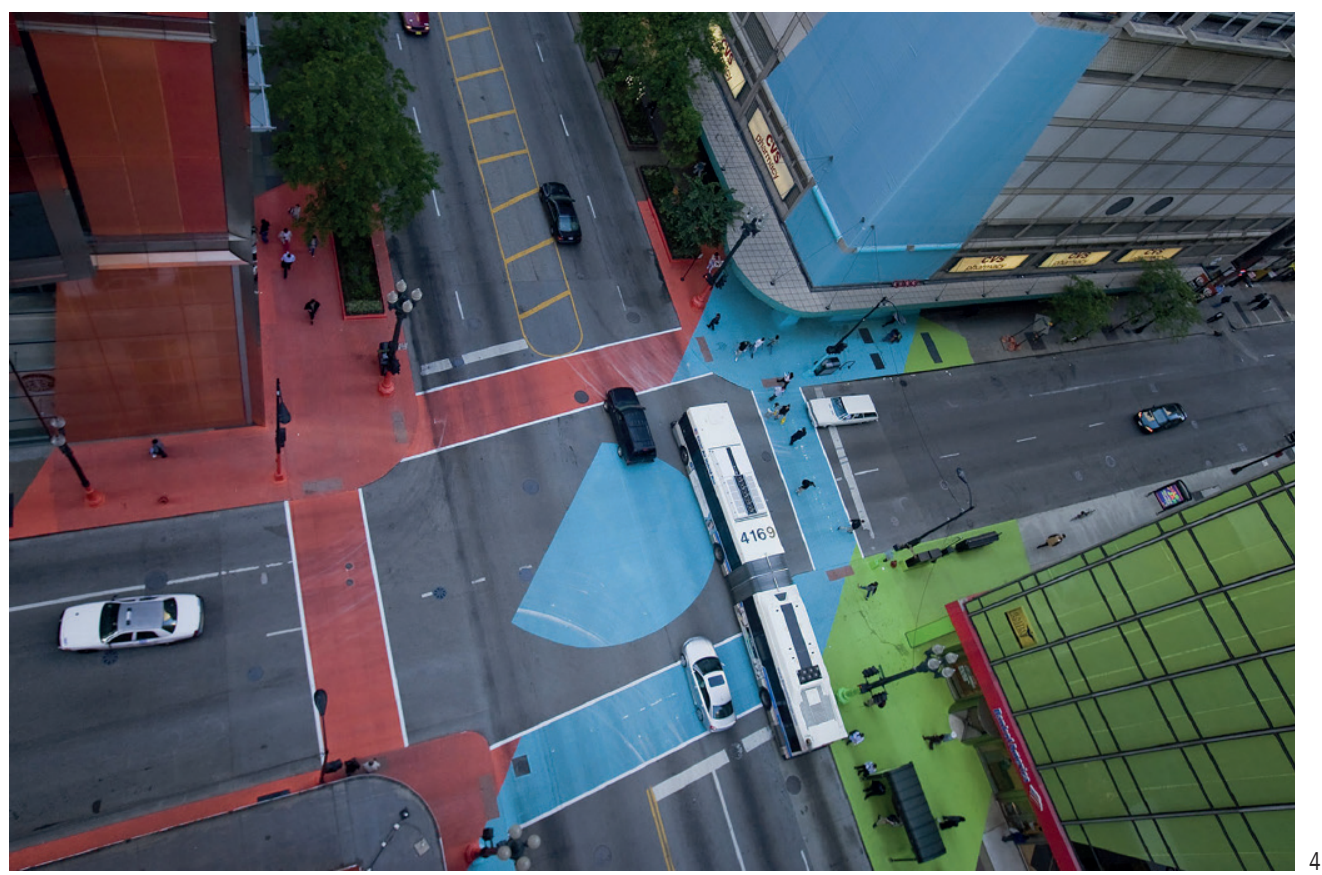

objetos que utiliza o un añadido extra mediante materia pictórica, "con la que integra los diferentes elementos que componen la pieza"19.

Son escasos los proyectos que la artista desarrolla en espacios exteriores, siendo uno de ellos Color Jam (2012) (ver figuras 4, 5 y 6) ${ }^{20}$, instalación de carácter temporal (de junio a septiembre) que formó parte de la programación de actividades culturales, danza y música, llevaba a cabo por el área comercial y cultural Chicago Loop Alliance ${ }^{21}$. En este caso, la artista no utiliza objetos para intervenir sobre el lugar seleccionado, la intersección entre las calles State y Adams, sino capas de color de vinilo adhesivo y de malla vinílica que fija
4, 5 y 6. Jessica Stockholder, vistas de la intervención Color Jam en la intersección de las calles State y Adams, Chicago, 2012. Presentado por la Chicago Loop Alliance. (c) Jessica Stockholder, cortesía de la artista y de MitchellInnes \& Nash, Nueva York. sobre el pavimento, el mobiliario urbano y la arquitectura de los edificios allí situados. Como se aprecia en la figura 4, "the volume of color intersecting the intersection was accommodating to the city's grid structure, and at the same time at odds with it"22, ya que la artista remarca mediante la aplicación de color los cuatro pasos peatonales de la intersección y las aceras colindantes, pero también sitúa en diagonal otros planos cromáticos que niegan la composición reticular del tejido urbano de la zona intervenida.

En esta ocasión, la paleta utilizada por la artista es más reducida que en otros proyectos, únicamente rojo, verde y azul; colores que son aplicados mediante tintas

19. KUNITZ, op. cit. supra, nota 16.

20. Las imágenes en color pueden verse en la página web de Jessica Stockholder: https://jessicastockholder.info/projects/art/color-jam/

21. BLAIR, Gwenda. At a Busy Intersection, Going Beyond Red, Yellow and Green. The New York Times [en línea]. Nueva York, 5 junio 2012 [consulta: $12-09$ 2020]. Disponible en: https://www.nytimes.com/2012/06/06/arts/design/color-jam-by-jessica-stockholder- opens-in-chicago.html

22. El volumen de color que cruzaba la intersección se acomodaba a la estructura de cuadrícula de la ciudad y, al mismo tiempo, estaba en desacuerdo con ella (traducción de las autoras). STOCKHOLDER, Jessica. Color Jam [en línea]. Jessica Stockholder website. Sin fecha [consulta: 06-09-2020]. Disponible en: https://jessicastockholder.info/projects/art/color-jam/ 

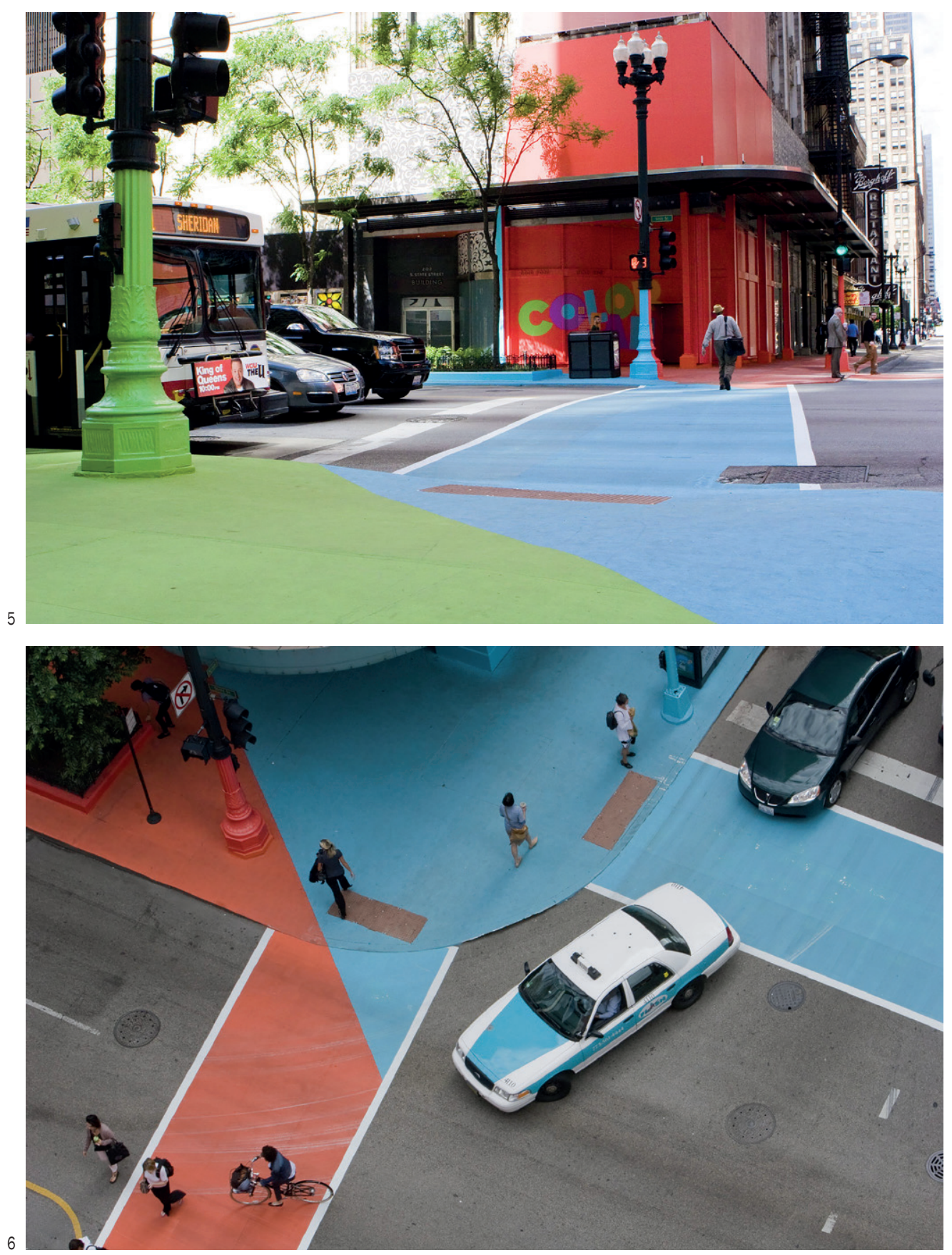

planas, sin degradados y delimitados perfectamente por las formas geométricas que los contienen. El color recubre las superficies como si fuese una segunda piel, adaptándose a sus irregularidades y volúmenes. Asimismo, los tonos empleados contrastan con el gris del pavimento y de los edificios intervenidos, añadiendo luminosidad al lugar y cierto carácter lúdico, propiciando la interactuación del viandante con el espacio, que, gracias a la intervención de Stockholder, repara en el lugar y lo experimenta de una forma más intensa y significativa. En este sentido, cabe mencionar que la intención de la Chicago Loop Alliance al patrocinar Color Jam fue activar el centro de la ciudad mediante el arte contemporáneo; por ello, mientras la intervención duró, actuó como zona de encuentro y de desarrollo de diferentes actividades, como conciertos o talleres artísticos. En esta obra el color interfiere en las propiedades de la arquitectura aportándole cierta singularidad, modificando la percepción de sus elementos 
7, 8 y 9. Katharina Grosse, Rockaway, 2016. Imágenes de la intervención en Fort Tilden, Rockaway Beach, Nueva York. (C) Katharina Grosse, VEGAP, Sevilla, 2021.

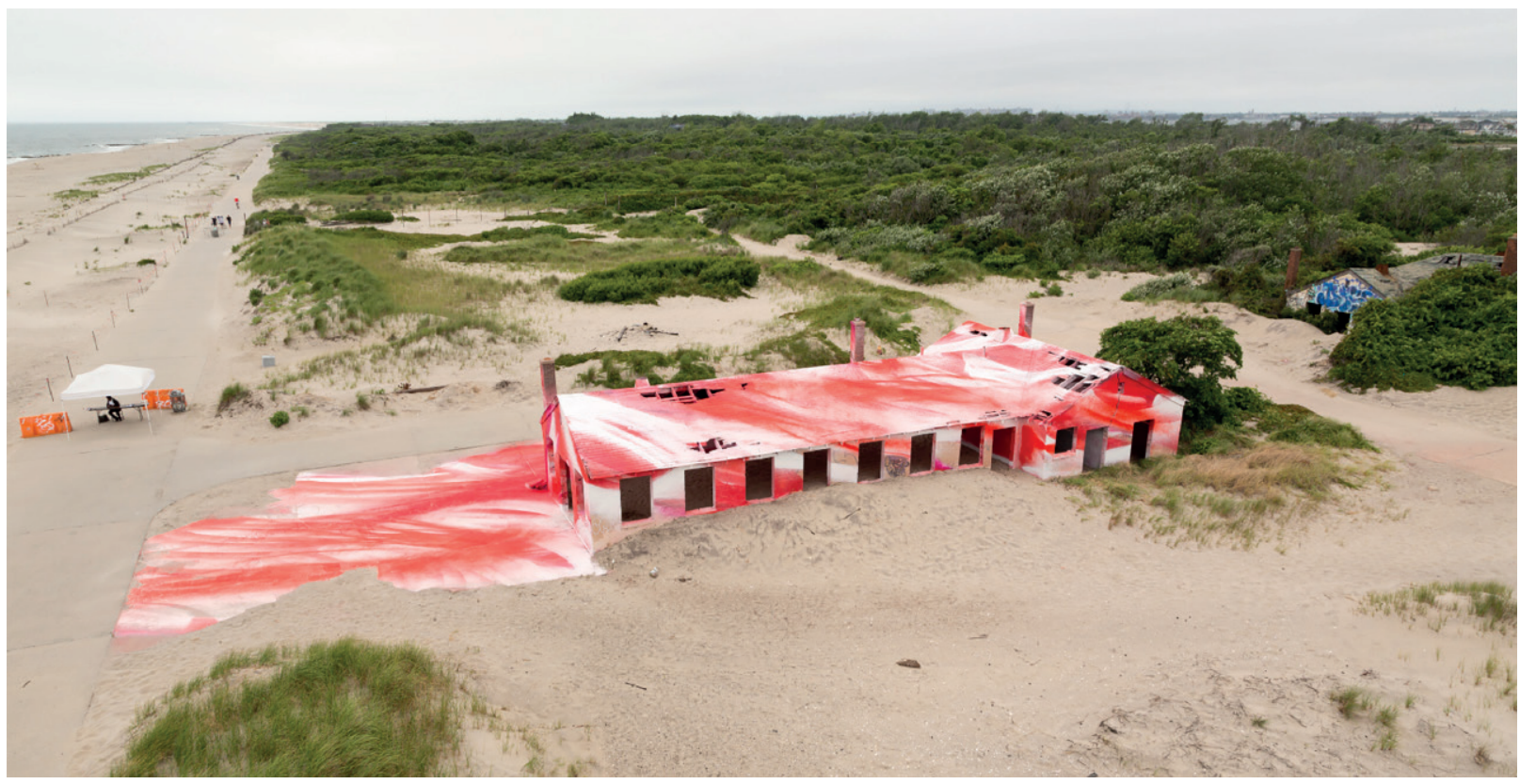

formales; pero también se aplica en algunas zonas con un sentido funcional, adaptándose, por ejemplo, a la demarcación de los pasos de peatones, como se ha comentado anteriormente. Igualmente, es usado atendiendo a valores puramente plásticos. Por todo ello, se concluye que en esta pieza la aplicación del color a la arquitectura y al espacio urbano responde a las tres estrategias cromáticas apuntadas por Juan Serra ${ }^{23}$.

\section{KATHARINA GROSSE: ROCKAWAY (2016)}

Katharina Grosse (Friburgo, 1961) comenzó a pintar con veinte años, tras estudiar en la Kunstakademie de Düsseldorf, pero ya desde niña prestaba atención a aspectos como las sombras que se generaban en la arquitectura, las cuales imaginaba borrar con color pues, para la artista, mirar el mundo estaba conectado con el hecho de hacer algo sobre y con él, según apunta Vanessa García-Osuna ${ }^{24}$. Con el paso de los años va trascendiendo en sus obras los límites físicos del soporte, así como ganando en monumentalidad a través del color, elemento que K. Grosse considera clave "porque provoca una resonancia inmediata en el espectador [...]. La elección del color puede realzar un espacio o un objeto de infinitas maneras. iPuede condicionar totalmente la experiencia! [...]. El color es el elemento transformador de superficies más mágico que existe. No tiene la obligación de estar en un lugar concreto. Puede aparecer en cualquier parte" 25 .

De todos sus proyectos se elige como caso de estudio la intervención Rockaway (2016) (ver figuras 7, 8 y 9) 26

\section{SERRA LLUCH, op. cit. supra, nota 3.}

24. GARCÍA-OSUNA, Vanessa. Katharina Grosse, la pintora sin límites. Tendencias del Mercado del Arte [en línea]. Febrero 2019 [consulta: 12-09-2020]. Disponible en: http://www.tendenciasdelarte.com/katharina-grosse-febrero-2019/

25. Ibíd.

26. Las imágenes en color pueden verse en la página web de Katharina Grosse: https://www.katharinagrosse.com/works/2016_4003 

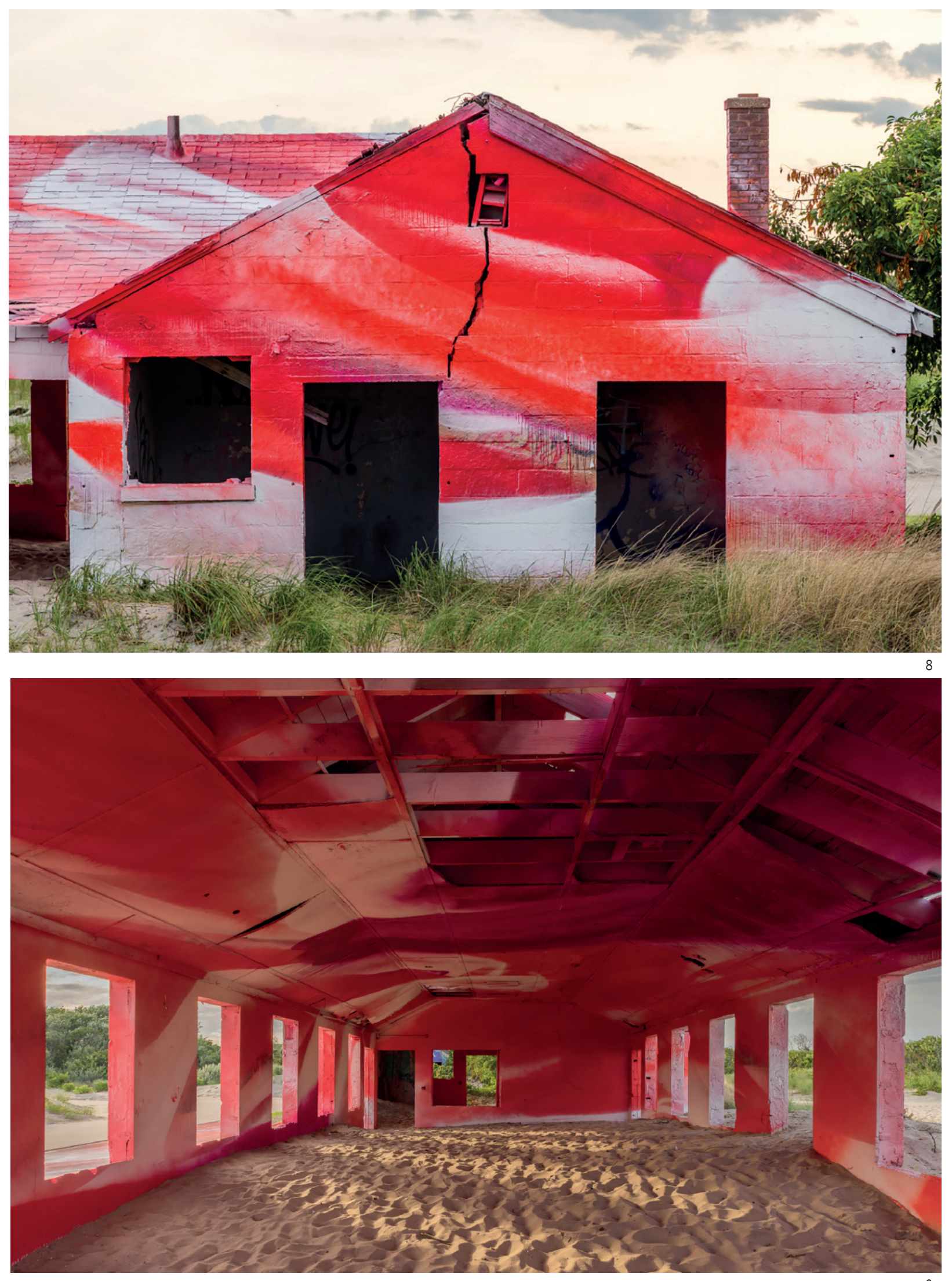
que, a diferencia de las propuestas analizadas de Krijn de Koning y Jessica Stockholder, se lleva a cabo en un entorno natural, aunque parcialmente urbanizado: la playa de la península de Rockaway, situada en el parque natural de Fort Tilden (Nueva York), donde se encuentra una antigua base del ejército estadounidense, que en la actualidad pertenece al Gateway National Recreation Area. Esta propuesta se considera importante por la forma en la que la artista aplica el color sobre la arquitectura, una instalación militar abandonada y devastada por el huracán Sandy en el año 2012. Grosse emplea una pistola de pintura a presión con mango, a veces desde una grúa para alcanzar las partes superiores del edificio y el tejado, que le sirve de extensión de su propio brazo, lo que genera como resultado una suerte de dripping difuminado y composición abierta all over, que cubre prácticamente el interior y exterior de toda la construcción original y parte del pavimento colindante ${ }^{27}$.

Rockaway fue encargada por el MoMA PS1 en colaboración con otras entidades, como la Jamaica BayRockaway Parks Conservancy o el Rockaway Beach Surf Club, como parte de su programa de recuperación de la península tras la gran devastación producida por el huracán Sandy. La artista trabaja con la arquitectura del edificio seleccionado desde planteamientos puramente formales, a partir de la carcasa que queda de este tras el paso del ciclón (figs. 7, 8 y 9). Grosse interviene en un espacio cargado de connotaciones, donde la memoria trágica del lugar parece rezumar por sus paredes. Condenado a ser demolido, con su intervención la artista dota al edificio de una nueva vida que, aunque fugaz, actúa a modo de homenaje previo a su desaparición. Al observar las imágenes de la obra da la sensación de que la intención de Grosse es la de borrar el pasado del edificio mediante la aplicación de diferentes capas de pintura en tonos rojizos, alternadas con blanco. Pero también recrear olas del mar que parecen envolver la construcción o golpearla, evocando así la acción del huracán sobre sus muros ${ }^{28}$.

En cuanto al proceso creativo, la primera acción que emprendió la artista fue la de pintar de blanco la arquitectura y ocultar todos los tags de grafiti que había sobre las paredes, tanto interiores como exteriores, ocultando así cualquier presencia cromática previa. Cabe mencionar que en la aplicación del color en la arquitectura inicial no se sigue ninguna estrategia cromática, por lo que la intervención de Grosse no supone ninguna modificación en este sentido, sino un añadido: la incorporación del color como un elemento nuevo que interviene en la percepción del edificio, pero con tanto protagonismo que anula prácticamente al resto de elementos arquitectónicos. Con base en lo anterior, se puede decir que la intervención de Grosse se ajusta a la estrategia I de Juan Serra ${ }^{29}$, en la que el color interfiere en las propiedades de la arquitectura desintegrándola, rompiendo su geometría característica, interfiriendo en la textura aparente y desarticulando los componentes de la forma arquitectónica. Así mismo, responde a la tercera estrategia, al potenciarse el valor intrínseco del color.

\section{HEATHER DAY: INTERVENCIÓN EN LA EMPRESA}

FLAX ART \& DESIGN (2016)

La artista norteamericana Heather Day (Hawái, 1989) trabaja la pintura abstracta lírica y gestual tanto en formatos y soportes transportables como sobre superficies arquitectónicas interiores y exteriores. Su proceso creativo es bastante visceral y pulsional, lo que le lleva a implicar todo su cuerpo en la génesis de cada obra, especialmente en las de mayores dimensiones, en una suerte de performance en la que resuenan ecos del action painting del expresionismo abstracto norteamericano ${ }^{30}$. En sus composiciones emplea una amplia paleta cromática que destaca por su armonía y por la presencia de diferentes

27. MUSEUM OF MODERN ART (MoMA). Katharina Grosse: Rockaway! | ARTIST STORIES [en línea]. Nueva York, 2016 [consulta: 07-09-2020]. Disponible en: https://www.youtube.com/watch?v=chhyDJnhlew

28. CASCONE, Sarah. Katharina Grosse Paints the Rockaways Red for the Summer. Artnet.news [en línea]. 3 julio 2016 [consulta: 07-09-2020]. Disponible en: https://news.artnet.com/exhibitions/moma-ps1-katharina-grosse-rockaway-537179

29. SERRA LLUCH, op. cit. supra, nota 3.

30. DAY, Heather. Studio Visit with Heather Day [vídeo en línea]. YouTube. 2020 [consulta: 20-09-2020]. Disponible en: https://youtu.be/93V-NwGbL2E 
contrastes: cálido-frío, luminosidad, cualitativo, de complementarios ${ }^{31}$, etc., según los casos. Otra característica de su obra es que puede interpretarse desde la sinestesia, al vincular determinadas sensaciones procedentes de un sentido con los de otro ${ }^{32}$.

De entre todos sus proyectos, se elige como objeto de análisis la primera intervención que desarrolla en el espacio público, siendo a su vez la obra de mayores dimensiones realizada por la artista hasta entonces, el año $2016^{33}$. Se trata de un proyecto para la empresa de materiales artísticos Flax Art and Design, concretamente para su sede situada entre las calles 15th y Martin Luther King Jr. Way, en el centro de la ciudad de Oakland (California), que cuenta con la colaboración de la Athen B. Gallery. Al tratarse de un hito en su trayectoria, la artista quiso innovar y no conformarse con la realización de un simple mural, decidió "to challenge the conventional and paint a new breed of mural; one that would start conversations and raise questions about spacial relationships and architecture"34. Para ello, interviene el revestimiento de dos laterales formando esquina de esta nave industrial, así como la acera colindante. Aunque la actuación sobre el pavimento no fue premeditada, sino que surgió después de percibir el potencial de unas gotas de pintura que cayeron sobre él, según declara la artista ${ }^{35}$, este accidente fue aprovechado por Day para otorgar una mayor profundidad a la obra, al ampliar sus planos compositivos, trascendiendo así la bidimensionalidad del lienzo tradicional.

Los vínculos entre la propuesta de la artista y su contexto arquitectónico y urbanístico se refuerzan mediante la incorporación en la pieza de las texturas del entorno, las grietas de la acera, la trama de los ladrillos de las paredes intervenidas, así como las sombras de los cables y postes telefónicos que se proyectan sobre el edificio a lo largo del día, con los que sus propios grafismos dialogan ${ }^{36}$ (ver figuras 10, 11 y 12). Resulta significativo cómo las manchas orgánicas y las líneas gestuales ejecutadas por Day se contraponen a la rigidez ortogonal de los ladrillos y otros elementos constructivos de la nave de Flax, consiguiendo de este modo el equilibrio compositivo. Por otra parte, y en opinión de Carolyn Mendle-Smith ${ }^{37}$, la dirección ascendente de algunos trazos y pinceladas provocan el efecto visual de que las paredes del edificio se expanden hacia el cielo, fusionándose con este; así mismo, las manchas de pintura ejecutadas sobre la acera invitan a los viandantes a entrar y caminar por la obra. Con todo ello, Day consigue ampliar la arquitectura, romper con su rigidez al desdibujar sus límites mediante su acción pictórica y, de este modo, hacer la ciudad más acogedora, objetivo último de la artista. En esta dirección, la creadora apunta: "The rough textures and high walls in cities often have negative connotations - they can make us feel unwelcome, or like we are being contained or perhaps even kept out. I wondered if architecture was just something we have to accept within a city, or if there were ways we can challenge it. How can we open up our city walls?"38. Para contribuir con su obra a la generación de un entorno urbano más saludable, considera imprescindible conversar con la vecindad mientras dura el proceso de ejecución de la pieza, y de este modo involucrarla en su desarrollo. La opinión de la comunidad es imprescindible

31. ITTEN, op. cit. supra, nota 8.

32. DAY, Heather. About [en línea]. Heather Day website. Sin fecha [consulta: 09-09-2020]. Disponible en: https://heatherday.com/about-cv

33. DAY, Heather. Walls to Paint Open: Painting the Mural in Downtown Oakland [en línea]. Blogger. 22 agosto 2016 [consulta: 06-09-2020]. Disponible en: https://heatherday.com/notes/2016/8/19/walls-to-paint-open

34. Ibíd. [Decidió] desafiar lo convencional y pintar una nueva generación de murales; una que iniciaría conversaciones y plantearía preguntas sobre las relaciones espaciales y la arquitectura (traducción de las autoras).

35. Ibíd.

36. Ibíd.

37. MENDLE-SMITH, Carolyn. Live Art with Heather Day [en línea]. Flax Art \& Desing blog. 15 agosto 2016 [consulta: 12-09-2020]. Disponible en: https://flaxart. com/flax-canvas/live-art-with-heather-day/

38. Las texturas ásperas y los altos muros de las ciudades a menudo tienen connotaciones negativas: pueden hacernos sentir incómodos o como si estuviéramos contenidos o incluso excluidos. Me preguntaba si la arquitectura era algo que teníamos que aceptar dentro de una ciudad, o si había formas de desafiarla. ¿Cómo podemos abrir las murallas de nuestra ciudad? (Traducción de las autoras). DAY, Heather, op. cit. supra, nota 33. 
10, 11 y 12. Heather Day, sin título, 2016. Intervención en la nave de la empresa Flax Art \& Design. Oakland, Estados Unidos. Heather Day website. Disponible en: https://heatherday.com/downtownoakland.
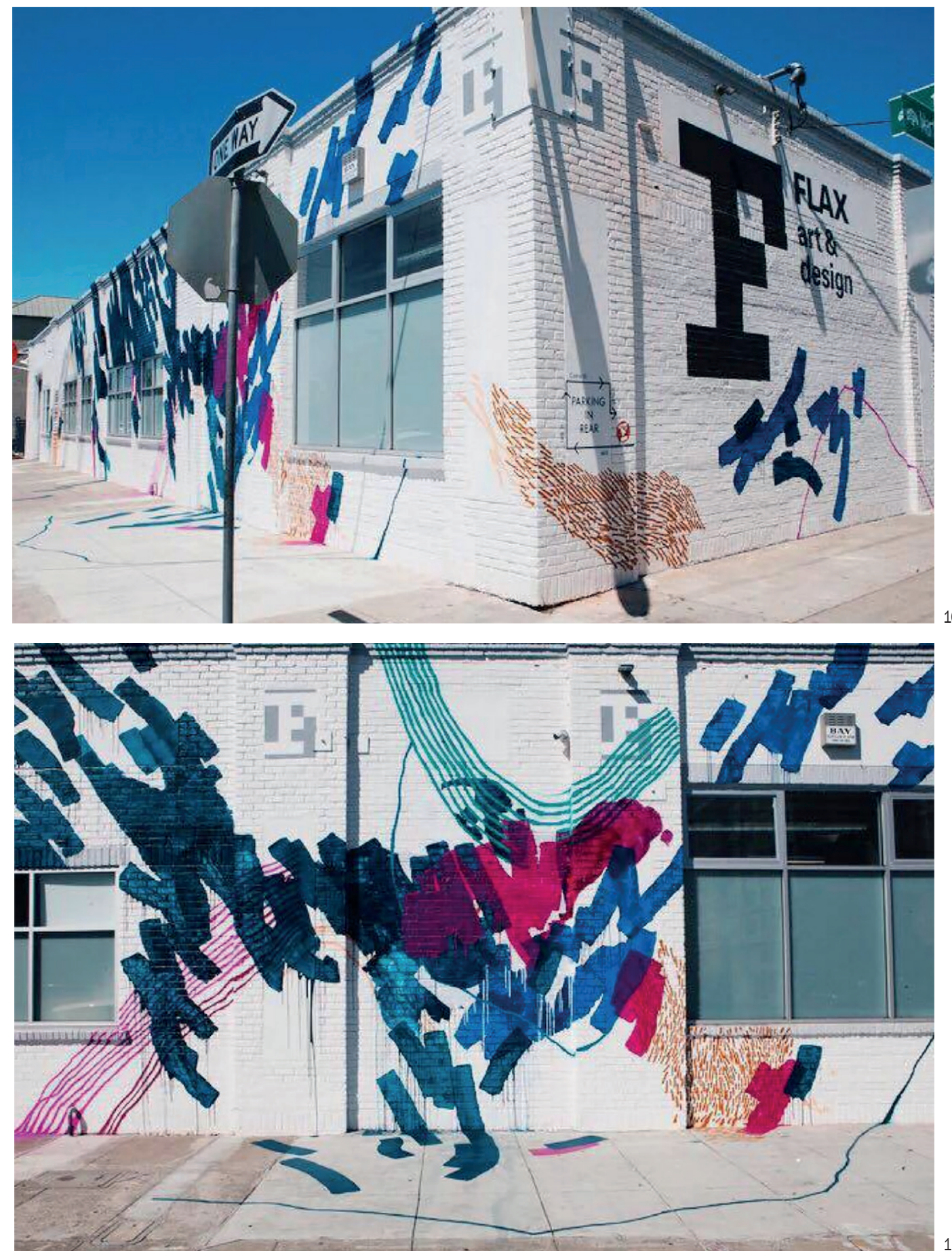


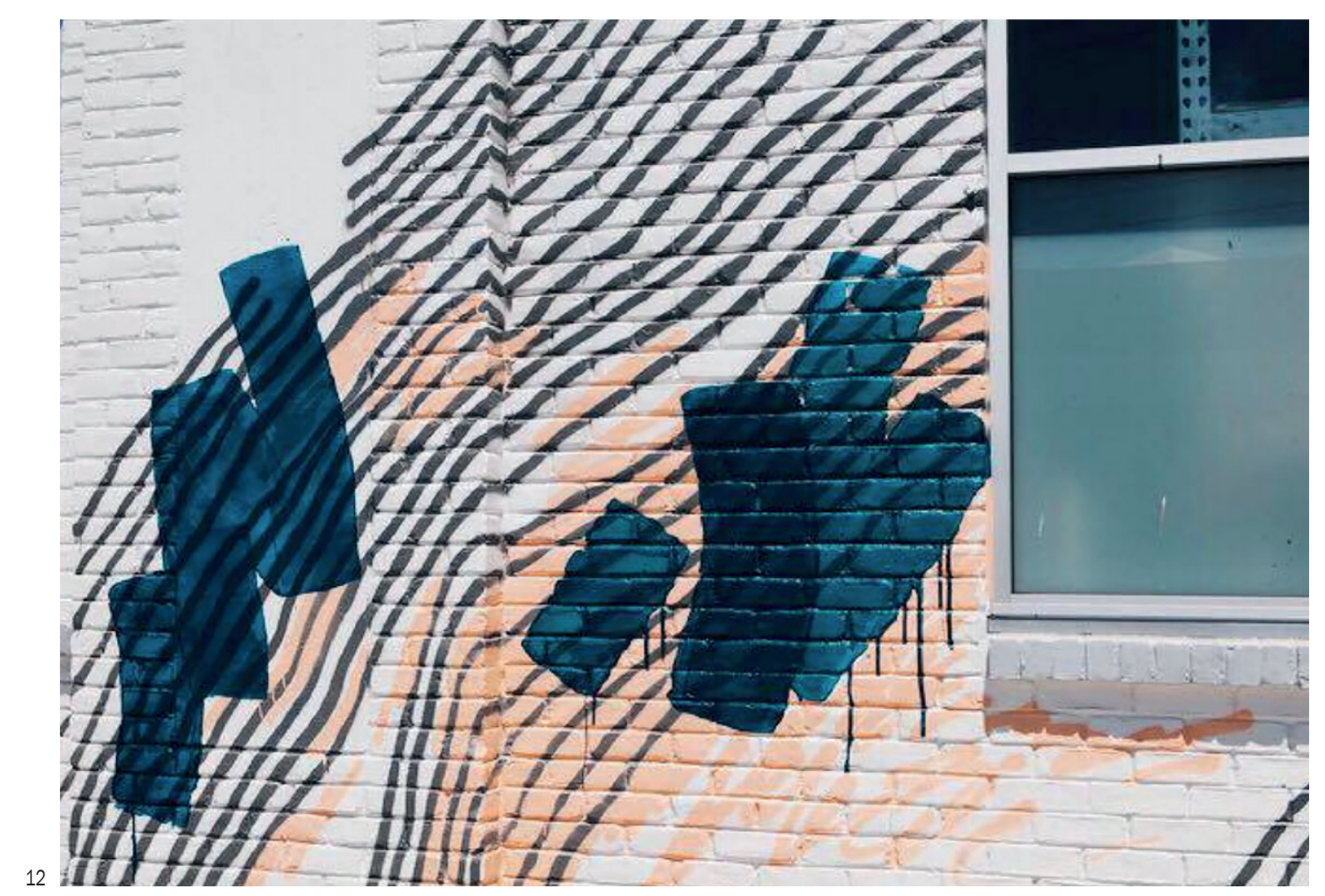

para completar la obra; de hecho, su valor radica precisamente en este aporte, según señala Day: "[... in the conversations we begin, the connections we create, and the legacy of relationships we foster along the way"39.

En cuanto a la gama cromática utilizada, predominan los tonos rojizos (magenta, rojo y naranja) y azules (prusia, cobalto y de manganeso), así como el gris, que contrastan en luminosidad y temperatura entre ellos, pero también con el fondo blanco de base del edificio, sobre el que se disponen y que no llegan a cubrir completamente. Se parte, por tanto, de un contexto arquitectónico cromáticamente neutro, en el que el color ha sido aplicado sin ninguna intención concreta, por lo que es en virtud de la acción pictórica de Day por la que este adquiere relevancia compositiva. De acuerdo con las estrategias cromáticas revisadas, el planteamiento de la artista se basaría en la estrategia I de Juan Serra ${ }^{40}$, debido a que el color interfiere en las propiedades visuales de la arquitectura integrándola con el entorno, fomentando "unique conversations and interactions with the surrounding space, shadows, passersby and the bright blue Oakland sky"41; pero también en la tercera, ya que es innegable la potencia

39. Ídem. En las conversaciones que iniciamos, en las conexiones que creamos y en el legado de las relaciones que fomentamos en el camino (traducción de las autoras).

40. SERRA LLUCH, op. cit. supra, nota 3.

41. Conversaciones e interacciones únicas con el espacio circundante, las sombras, los transeúntes y el cielo azul brillante de Oakland (traducción de las autoras). MENDLE-SMITH, op. cit. supra, nota 37. 
visual que tienen las manchas y gestos de la artista en sí mismos.

\section{DISCUSIÓN Y CONCLUSIONES}

El urbanismo táctico es definido por autores como Mike Lydon $^{42}$, Marisol García y Javier Vergara ${ }^{43}$ o Antonio R. Montesinos ${ }^{44}$ como aquellas acciones encaminadas a transformar las ciudades para mejorar la vida en ellas, que favorecen la proactividad de la ciudadanía frente a las problemáticas urbanas contemporáneas y que son impulsadas tanto por colectivos vecinales y organizaciones locales como por instituciones públicas y privadas mediante un proceso colaborativo. Implican soluciones creativas (autorizadas o no) ejecutadas con pocos recursos, de desarrollo flexible, pequeña escala, ámbito local, carácter temporal, expectativas realistas y que, en el caso de funcionar, pueden derivar en acciones planificadas y de mayor envergadura y permanencia en el tiempo. Analizadas desde esta perspectiva, las cuatro intervenciones pictóricas revisadas en este artículo comparten algunas de las características citadas, si bien no todas ellas, incorporándolas en su desarrollo de una manera muy particular según cada caso, como se expone a continuación.

The museum of gravity no tiene un propósito claramente "táctico", salvo el de hacer más visible el patrimonio histórico y cuestionar su supuesta veracidad, contribuyendo al mismo tiempo a activar económicamente la zona, al atraer visitantes hacia la abadía y su museo. Al formar parte de la Trienal de Arte Beaufort 03, puede considerarse que la obra es fruto de la colaboración entre el artista y diferentes entidades implicadas en su organización, aunque la autoría le corresponda exclusivamente a él. Presenta asimismo otros rasgos, como la duración limitada, un coste no demasiado elevado y un tamaño no desmesurado, que alinean esta propuesta con los planteamientos del urbanismo táctico.

Color Jam: esta intervención es encargada por una organización vecinal con la pretensión de activar su distrito a nivel comercial y cultural. Para poder desarrollarse, fue necesario contar con la aprobación de los propietarios de las viviendas y los locales afectados por la obra, aunque estos no intervinieron en su ideación, labor que asumió Stockholder en solitario, según nos informa en una comunicación personal45. La artista declara asimismo que su intención al intervenir sobre los pasos peatonales no es la de potenciar su visibilidad, alejándose, por tanto, de la táctica de "reparación de intersecciones" formulada por Mike Lydon ${ }^{46}$. Sin embargo, el hecho de que la obra fuese utilizada como meeting point y lugar para el desarrollo de diferentes actividades la dota de la función, no prevista por la artista, de recuperar la calle como espacio para la reunión pública, aspecto que recoge la citada táctica, al igual que su carácter temporal.

Rockaway: al igual que los dos anteriores, este proyecto es patrocinado por una serie de organismos públicos y privados, en este caso para celebrar la recuperación de la península Rockaway tras la devastación ocasionada por el huracán Sandy. En este sentido, se puede hablar de que la obra surge de una colaboración, aunque en ningún momento los promotores intervengan en su desarrollo formal y conceptual. Se trata de un proyecto temporal que pone el foco de atención sobre un edificio que va a ser demolido, como otros muchos que se encuentran diseminados por la zona, acabando con los vestigios de una época marcada por un uso militar del territorio para pasar a otra caracterizada por su adscripción a la figura de parque natural y su disfrute por parte de la sociedad civil. En este sentido, la obra podría ubicarse dentro del

42. LYDON, Mike. Urbanismo Táctico 2. Acción a corto plazo // cambio a largo plazo [en línea]. Traducido al castellano por A. KOGAN, K. STEFFENS, y J. VERGARA. Miami-Nueva York: Street Plans, 2012 [consulta: 03-02-2021]. Disponible en: https://issuu.com/streetplanscollaborative/docs/urbanismo_tactico_2_digital_edition

43. GARCÍA, Marisol; VERGARA, Javier. Urbanismo Táctico 3. Casos Latinoamericanos [en línea]. Nueva York-Miami: Street Plans; Chile: Fundación Ciudad Emergente, 2013 [consulta: 04-02-2021]. Disponible en: https://issuu.com/eduartpit/docs/174221684-urbanismo-tactico-casos-I

44. MONTESINOS, Antonio R. Urbanismo táctico. Arquitasa [en línea]. 15 julio 2020 [consulta: 02-02-2021]. Disponible en: https://arquitasa.com/urbanismo-tactico/ 45. Comunicación personal con la artista llevada a cabo el 1 de febrero de 2021.

46. LYDON, op. cit. supra, nota 42. 
urbanismo táctico, aunque este planteamiento escape a la intencionalidad de Grosse.

La intervención en la empresa Flax Art \& Design es la única obra que está pensada con un carácter permanente, pero también es la única en contar con la opinión de la vecindad durante su materialización, demostrando su creadora una clara preocupación por cómo será recibida y percibida por los habitantes del barrio en el que se ubica. Al proyectar la intervención pensando en actuar sobre la arquitectura para crear ciudades más amigables, Day se posiciona de forma no premeditada dentro del urbanismo táctico, cumpliendo, además, con otras características de este fenómeno, como la flexibilidad (la obra se va modificando a medida que se va ejecutando), una escala abarcable, presupuesto bajo o ámbito local.

Antonio R. Montesinos afirma que las actuaciones enmarcadas dentro del urbanismo táctico contribuyen a que "nuestras ciudades evolucionen hacia espacios más estéticos y más humanos"47. En su opinión ${ }^{48}$, estas acciones deben buscar el equilibrio entre la usabilidad y el diseño, ya que las propuestas con un desarrollo más gráfico o plástico producen una experiencia más satisfactoria al ciudadano. El valor que este autor otorga a la estética aproxima las cuatro intervenciones pictóricas analizadas a este fenómeno, ya que en todas los aspectos formales están muy cuidados, no en vano, están creadas por artistas. A la función estética se añade la de señalización de un determinado edificio o zona urbana, así como otras que han ido viéndose de forma particular al analizar cada uno de los proyectos seleccionados. Por ello, hay que entenderlas como prácticas alejadas de una interpretación puramente decorativista, ya que incluso la aplicación del color en ellas responde a unas estrategias concretas, vinculadas al contexto arquitectónico sobre el que se desarrollan o a criterios puramente metapictóricos, pero que en ningún caso atentan contra el edificio intervenido -ni siquiera cuando este es de índole patrimonial-, bien por su carácter efímero o reversible-como ocurre en The museum of gravity o en
Color Jam-, por actuar sobre una construcción que después va a ser demolida -como es el caso de Rockaway-, o bien por la incorporación de los elementos constructivos y texturas del edificio y del entorno a la propia obra -como sucede en la intervención de Heather Day-. Los cuatro proyectos objeto de estudio se distancian, por tanto, del debate surgido a raíz de los recientes casos del Polideportivo Miguel Fisac (Getafe) o del Faro de Ajo (Cantabria), cuyas cualidades materiales, estéticas y estilísticas han sido alteradas mediante la acción pictórica del Colectivo Boa Mistura y Okuda San Miguel, respectivamente, lo que ha sido considerado por algunos autores como un menosprecio del valor histórico de la arquitectura original.

Finalmente, cabe mencionar que todas las intervenciones analizadas se disponen sobre construcciones previas en la que el color es neutro (gris, tonos tierra o blanco), procediendo de los propios materiales constructivos o de materia pictórica añadida, en el caso de la tienda de Flax Art \& Design. Por lo tanto, en el diseño arquitectónico original no se sigue ninguna de las estrategias cromáticas teorizadas por Juan Serra, sino que es la intervención pictórica posterior la que posibilita una lectura en este sentido. De los tres mecanismos cromáticos señalados por este autor, se observa que en las propuestas de Krijn de Koning y de Jessica Stockholder se aplican los tres, mientras que las de Katherina Grosse y Heather Day solo responden a dos, la primera y la tercera. Este dato induce a pensar en una posible relación entre el tipo de abstracción al que se adscribe la intervención pictórica realizada y la aplicación de unas estrategias cromáticas u otras. Por otra parte, en los cuatro casos estudiados el color dota de singularidad a la construcción o zona urbana sobre la que se aplica, destacando entre otras arquitecturas del entorno. Este rasgo se opone al de mimetismo del edificio con el paisaje, que también puede ser conseguido mediante la aplicación del color, según señala Serra ${ }^{49}$, pero que no es el caso de las obras objeto de estudio.

47. MONTESINOS, op. cit. supra, nota 44.

48. MONTESINOS, Antonio R. Urbanismo táctico 2. Arquitasa [en línea]. 19 agosto 2020 [consulta: 02-02-2021]. Disponible en: https://arquitasa.com/arqticulos/urbanismo-tactico-2/

49. SERRA LLUCH, Juan. Color for Architects. San Francisco: Chronicle Books, 2019. 
Este artículo recoge los resultados de proyecto de investigación I+D+i “El barrio como escenario de pedagogías críticas y arte colaborativo PGC2018094351-B-C42)", financiado por el Programa Estatal de Generación de Conocimiento y Fortalecimiento Científico y Tecnológico del Ministerio de Ciencia, Innovación y Universidades.

Aportación de cada autor:

Aurora Alcaide-Ramírez (AA-R): Conceptualización, curación de los datos, revisión y edición del documento final. Desarrollo de la investigación, diseño de la metodología y redacción del artículo.

Ana Ruiz-Abellón (AR-A): Búsqueda bibliográfica, selección y edición de las imágenes y gestión de los permisos para su publicación. Desarrollo de la investigación, diseño de la metodología y redacción del artículo.

Autoría: AA-R y AR-A (50\% - 50\%)

\section{Bibliografía citada}

ARCHER, Nate. Krijn de Koning: The museum of gravity. Designboom magazine [en línea]. Milán, Italia, 6 octubre 2009 [consulta: 03-09-2020]. Disponible en: https://www.designboom.com/architecture/krijn-de-koning-the-museum-of-gravity/

ARDENNE, Paul. Arte contextual. Creación artística en medio urbano, en situación, de intervención, de participación. Murcia: CENDEAC, 2006.

Beaufort Triennale. Artmap. Sin fecha [consulta: 03-02-2021]. Disponible en: https://artmap.com/beauforttriennale/exhibition/beaufort032009-2009? print=do

BLAIR, Gwenda. At a Busy Intersection, Going Beyond Red, Yellow and Green. The New York Times [en línea]. Nueva York, 5 junio 2012 [consulta: $12-$ 09-2020]. Disponible en: https://www.nytimes.com/2012/06/06/arts/design/color-jam-by-jessica-stockholder- opens-in-chicago.html

CASCONE, Sarah. Katharina Grosse Paints the Rockaways Red for the Summer. Artnet.news [en línea]. 3 julio 2016 [consulta: 07-09-2020]. Disponible en: https://news.artnet.com/exhibitions/moma-ps1-katharina-grosse-rockaway-537179

DAY, Heather. About [en línea]. Heather Day website. Sin fecha [consulta: 09-09-2020]. Disponible en: https://heatherday.com/about-cv

DAY, Heather. Walls to Paint Open: Painting the Mural in Downtown Oakland [en línea]. Blogger. 22 agosto 2016 [consulta: 06-09-2020]. Disponible en: https://heatherday.com/notes/2016/8/19/walls-to-paint-open

DAY, Heather. Studio Visit with Heather Day [vídeo en línea]. YouTube. 2020 [consulta: 20-09-2020]. Disponible en: https://youtu.be/93V-NwGbL2E FERNÁNDEZ CONSUEGRA, Celia Balbina. Internacional Situacionista, movimiento precursor del performance art. En: index.comunicación [en línea]. Madrid: Universidad Rey Juan Carlos, 2014, vol. 4, n. ${ }^{0}$ 1, pp. 123-147 [consulta: 10-09-2020]. E-ISSN 2174-1859. Disponible en: https://journals.sfu. ca/indexcomunicacion/index.php/indexcomunicacion/article/view/128/146

FERNÁNDEZ FARIÑA, Almudena. Lo que la pintura no es. La lógica de la negación como afirmación del campo expandido en la pintura. Pontevedra: Diputación de Pontevedra, 2009.

FERNÁNDEZ FARIÑA, Almudena. Pintura site. Santiago de Compostela: Dardo, 2014.

GARCÍA, Marisol; VERGARA, Javier. Urbanismo Táctico 3. Casos Latinoamericanos [en línea]. Nueva York-Miami: Street Plans; Chile: Fundación Ciudad Emergente, 2013 [consulta: 04-02-2021]. Disponible en: https://issuu.com/eduartpit/docs/174221684-urbanismo-tactico-casos-I

GARCÍA-OSUNA, Vanessa. Katharina Grosse, la pintora sin límites. Tendencias del Mercado del Arte [en línea]. Febrero 2019 [consulta: 12-09-2020]. Disponible en: http://www.tendenciasdelarte.com/katharina-grosse-febrero-2019/

GARI, Joan. La conversación mural. Ensayo para una lectura del graffiti. Madrid: Fundesco, 1995.

ITTEN, Johannes. El arte del color. Aproximación subjetiva y descripción objetiva del arte. Traducido al castellano por V. LAMÍQUIZ. París: Bouret, 1975.

Original publicado en 1961. 
KONING, Krijn de. Texts, Interviews, Articles. Krijn the Koning - Works. Sin fecha [consulta: 10-09-2020]. Disponible en: https://www.krijndekoning. $\mathrm{nl} /$ texts/index.html

KUNITZ, Jorge. Jessica Stockholder: "El color es el alma de mi trabajo". Tendencias del Mercado del Arte [en línea]. Enero 2012 [consulta: 11-092020]. Disponible en: http://www.tendenciasdelarte.com/jessica-stockholder-enero-2012/

LYDON, Mike. Urbanismo Táctico 2. Acción a corto plazo // cambio a largo plazo [en línea]. Traducido al castellano por A. KOGAN, K. STEFFENS, J. VERGARA. Miami-Nueva York: Street Plans, 2012 [consulta: 03-02-2021]. Disponible en: https://issuu.com/streetplanscollaborative/docs/urbanismo_tactico_2_digital_edition

MADERUELO, Javier. La idea de espacio en el arte y la arquitectura contemporáneos 1960-1989. Madrid: Akal, 2008.

MENDLE-SMITH, Carolyn. Live Art with Heather Day [en línea]. Flax Art \& Desing blog. 15 agosto 2016 [consulta: 12-09-2020]. Disponible en: https:// flaxart.com/flax-canvas/live-art-with-heather-day/

MONTESINOS, Antonio R. Urbanismo táctico. Arquitasa [en línea]. 15 julio 2020 [consulta: 02-02-2021]. Disponible en: https://arquitasa.com/ urbanismo-tactico/

MONTESINOS, Antonio R. Urbanismo táctico 2. Arquitasa [en línea]. 19 agosto 2020 [consulta: 02-02-2021]. Disponible en: https://arquitasa.com/ arqticulos/urbanismo-tactico-2/

MUSEUM OF MODERN ART (MoMA). Katharina Grosse: Rockaway! | Artist Stories [en línea]. Nueva York, 2016 [consulta: 07-09-2020]. Disponible en: https://www.youtube.com/watch?v=chhyDJnhlew

PEIRÓ LÓPEZ, Juan Bautista. El muro como soporte en la pintura contemporánea: anotaciones marginales. En: Arte público hoy: nuevas vías de consideración e interpretación crítica. Actas del Congreso Internacional de Críticos de Arte. España: ACYLCA y AECA, 2009, pp. 159-167.

SERRA LLUCH, Juan. La versatilidad del color en la composición de la arquitectura contemporánea europea: contexto artístico, estrategias plásticas e intenciones [en línea]. Directora: Ángela García Codoñer. Tesis doctoral. Universidad Politécnica de Valencia, Departamento de Expresión Gráfica Arquitectónica. TESE0, 2010 [consulta: 03-09-2020]. Disponible en: https://www.educacion.gob.es/teseo/imprimirFicheroTesis. do?idFichero=\%2FappnNbNLRQ\%3D

SERRA LLUCH, Juan. Color for Architects. San Francisco: Chronicle Books, 2019.

SLEWE GALLERIE. Krijn de Koning - Bio [en línea]. Amsterdam, sin fecha [consulta: 04-09-2020]. Disponible en: https://www.slewe.nl/artists/ krijndekoning

STOCKHOLDER, Jessica. Color Jam [en línea]. Jessica Stockholder website. Sin fecha [consulta: 06-09-2020]. Disponible en: https://jessicastockholder.info/projects/art/color-jam/

Aurora Alcaide-Ramírez (Córdoba, 1975). Doctora en Bellas Artes por la UGR (2003). Profesora Titular de la Facultad de BB.AA de la Universidad de Murcia. Es directora del Grupo de Investigación Arte y Políticas de Identidad y subdirectora de la revista homónima. Actualmente participa en el proyecto I+D+i El barrio como escenario de pedagogías críticas y arte colaborativo (PGC2018094351-B-C42). Entre sus publicaciones destacan: "Zoom a la inmigración: creadoras colombianas en España. Aproximaciones a dos casos de estudio", en Creadoras de imágenes. Mujer y transmedialidad (77-96), Academia del Hispanismo (2020); "Autobiografía, memoria e identidad en la obra de mujeres artistas migrantes. Estudio comparativo entre las creaciones de la puertorriqueña Brenda Cruz y la cubana Gertrudis Rivalta”, Centro Journal, XXIX (I), spring 2016, 152-183, y “Creativismo 'glocal' y antropófago: la poética expresiva de César Martínez", en Brincando fronteras. Creaciones locales mexicanas y globalización, CONACULTA (México, 2012).

Ana Ruiz-Abellón (Murcia, 1991). Graduada en Bellas Artes (2014), Máster en Producción y Gestión Artística (2016) y Doctora en Artes y Humanidades por la Universidad de Murcia (2020). En la actualidad participa en el proyecto I+D+i El barrio como escenario de pedagogías críticas y arte colaborativo (PGC2018-094351-B-C42). Sus publicaciones abordan el estudio de proyectos pictóricos realizados en el espacio urbano, donde el color es el protagonista como "Nuevas formas de pintar. Marlon de Azambuja y la transformación plástica del espacio urbano", Arte y Sociedad, n¹3 (2017) o "La ciudad como espacio de nuevas creaciones artísticas: el caso de Potencial escultórico", revista URBS, 7(2) (2017). Ha presentado sus investigaciones en diferentes congresos, como De Sur a Sur, UGR (2017), el International Congress on Contemporary European Painting, Universidad de Oporto (2017) o el I/ Congreso Internacional Arte y Políicas de Identidad, UM (2019). 


\section{Autor imagen y fuente bibliográfica de procedencia}

Información facilitada por los autores de los artículos:

página 19, 1. WOODBRIDGE, Kenneth. Princely Gardens. Nueva York: Rizzoli, 1986; página 21, 2. ALPHAND, J. C. Adolphe. Les Promenades de Paris. Princeton: Princeton Architectural Press, 1984, p. 199; página 22, 3. AURICOSTE, Isabelle; TONKA, Hubert. Parc Ville Villette. Seyssel: Champ Vallon, 1987; páginas 23,24 y 25, 4, 5 y 6. Fotografías de Ramón R. Llera; páginas 26 y 27, 7 y 8 . BASSO PERESSUT, Luca; CALIARI, Pier Federico, eds. Piranesi Prix de Rome. Progetti per la nuova Via dei Fori Imperiali. Roma: Aión Edizioni, 2017; página 28, 9. LAB/PAP Laboratorio de Paisaje Arquitectónico, Patrimonial y Cultural; páginas 28 y 29, 10, 11 y 12 . BASSO PERESSUT, Luca; CALIARI, Pier Federico, eds. Piranesi Prix de Rome. Progetti per la nuova Via dei Fori Imperiali. Roma: Aión Edizioni, 2017; páginas 30 y 31 ,13, 14 y 15. ÁLVAREZ, Darío; IGLESIA, Miguel Ángel de la. Modelos de paisajes patrimoniales. Estrategias de protección e intervención arquitectónica. Valladolid: LAB/PAP y Departamento de Teoría de la Arquitectura y Proyectos Arquitectónicos, Universidad de Valladolid, 2017; página 36, 1. Philippe BOURDIN, “Le sacre de Louis XV", Histoire par l'image [en línea], consultado el 20 de agosto de 2020. Disponible en: http://histoire-image.org/fr/etudes/sacre-louis-xv; página 37, 2. Archivo de José lgnacio Linazasoro Rodríguez; página 38, 3. JAKOVUEVIC, Nada; CULOT, Maurice, dirs. Places et monuments. Bruselas: Mardaga, 1984; página 40, 4. RIGAUD, Olivier. Les plans anciens de Reims, 16001825. Dossier iconographique. Reims: RHA, 1991; página 41, 5. Biblioteca Municipal de Reims [en línea], consultado el 20 de agosto de 2020. Disponible en: https:// commons.wikimedia.org/wiki/File:Rue_Libergier_Cathédrale_Reims_Varin_30131.jpg; página 42, 6. Revista UR, 1985, n. ${ }^{\circ}$ 2; página 43, 44, 46, 47, 48, 49, 50, 7, 8, 9 , 10, 11, 12, 13, 14, 15. Archivo de José Ignacio Linazasoro Rodríguez; página 54, 1. Eisenman Architects Archives; página 55, 2. DR2004:0360:003 Cedric Price fonds Canadian Centre for Architecture; página 56, 3. DR2004:0355:007. Cedric Price fonds Canadian Centre for Architecture; página 57, 4. DR2004:0355:006. Cedric Price fonds. Canadian Centre for Architecture; página 59, 5. ARCH267828. IFCCA Prize Competition for the Design of Cities fonds Canadian Centre for Architecture; página 59, 6. Dominio público.; página 60, 7. Archivo Lacaton \& Vassal; página 61, 8. Fotomontaje de los autores a partir de Google Street View (2018); página 62, 9. Fotografía de Philippe Ruault:; página 63, 10. Muestra de la web del proyecto con el reportaje fotográfico de Philippe Ruault.; página 64,11 . Archivo Lacaton \& Vassal.; página 65,12 . Vista aérea en Google Maps (2018):; página 65, 13. Vista obtenida en Google Street View (2018); página 66, 14. Archivo Lacaton \& Vassal, 2004.; página 67, 15. Vista obtenida a través de Google Street View (2018); páginas 74 y 75, 1, 2 y 3. @ Krijn de Koning, cortesía del artista; páginas 76 y 77, 4, 5 y 6 . @ Jessica Stockholder, cortesía de la artista y de Mitchell-Innes \& Nash, Nueva York; páginas ,78 y 79, 7, 8 y 9. @ Katharina Grosse, VEGAP, Sevilla, 2021; páginas 82 y 83, 10 , 11 y 12. Heather Day website. Disponible en: https://heatherday.com/downtownoakland; página 90, 1. Universidad de Zaragoza. Unidad Técnica de Construcciones.; página 91, 2. Planimetría redibujada por Clara Dobón Ricarte.; página 92, 3. Planos, redibujada por Clara Dobón Ricarte. Fotografías cortesía de la Facultad de Derecho de la Universidad de Zaragoza.; página 93, 4. Google Maps.; página 94, 5. Fotografías de los autores.; página 95, 6. Proyecto de Ejecución, Ampliación y Reforma de la Facultad de Derecho (Zaragoza). Fuente: Universidad de Zaragoza. Unidad Técnica de Construcciones.; páginas 96 y 98, 7, 8. Planos y axonometría dibujados por Clara Dobón Ricarte; páginas 99 y 101, 9, 10, 11. Fotografías de los autores.; página 102, 12. Fotografía (izquierda) de los autores y fotografía (derecha) cortesía de la Facultad de Derecho de la Universidad de Zaragoza.; página 102, 13. Fotografías de los autores.; página 103, 14. Fotografía cortesía de Javier López Sánchez, decano de la Facultad de Derecho de la Universidad de Zaragoza.; página 104, 15. Proyecto de Ejecución, Ampliación y Reforma de la Facultad de Derecho (Zaragoza). Fuente: Universidad de Zaragoza. Unidad Técnica de Construcciones; página 108, 1. Dibujos del autor; página 109, 2. Ayuntamiento de Madrid; página 110 y 112, 3 y 4. Ayuntamiento de Madrid; página 113 y 114, 5 y 6 . Archivo Cabrero; página 115, 7. Reconstitución gráfica del autor; página 116, 8. Legado 2 Fundación COAM; página 117, 9. Dibujos del autor; página 118, 10. Arquitectura, 1959, n. 7 y Francisco de Asís Cabrero y Jaime Ruiz; página 119, 11. Archivo Cabrero; página 120, 12. Dibujos del autor; página 120, 13. Fotografía del autor; página 121, 14. Dibujos del autor; página 122, 15. Fotografía del autor. 
CUANDO LA PINTURA AMPLÍA LA ARQUITECTURA: INTERVENCIONES REALIZADAS EN EL ESPACIO PÚBLICO WHEN PAINTING ENHANCES ARCHITECTURE: INTERVENTIONS IN A PUBLIC SETTING

Aurora Alcaide-Ramírez (https://orcid.org/0000-0001-5983-4200)

Ana Ruiz-Abellón (https://orcid.org/0000-0003-0885-0088)

p.71 INTRODUCTION

All through the $20^{\text {th }}$ century, specifically from the 1960 s onwards, different pictorial interventions have been carried out in many cities. Those tend to modify the outer appearance of buildings and public space overall. Referred to as mural painting, graffiti, post-graffiti, site painting, site specific, urban/street art, public art, contextual art, or expandedfield painting, depending on the case and according to the different authors, ${ }^{1}$ these artistic practices not only act upon the cities on an aesthetic level, but also can have an effect on the initial perception of the architectural shapes, and they can be a means at the service of the artist's personal expression or the citizens' statements and demands. Furthermore, they can set up a conversation with diverse backgrounds, be it social, cultural, economic, or territorial -and inherent formal features-; they can modify the emotional experience (psychogeography) ${ }^{2}$ of any given area in the city, turning them into more inhabitable cities. Also, any given place can be marked off with them, becoming a landmark for pedestrians, but they can bring art closer to society, asking on occasion for citizens' involvement in the origin and development of a work, and so on. Ultimately, those pictorial actions -carried out on the urban fabrictend to enhance its sense and meaning, allowing for other ways of experiencing and understanding the city and its architectural elements.

p.72 Within those artistic practices, this paper will focus on the ones developed in Europe and North America in the $21^{\text {st }}$ century, and whose leading role is played by colour, an element from the language of visual arts that takes on the part of mediator between the disciplines of painting and architecture, by means of abstract compositions that expand over the building walls, the pavement, the road surface, and the urban furniture; all in all, it invigorates the architecture and surrounding elements. Therefore, the proposals with a medium or a high level of iconicity, in which the conveyed motif hoards the compositional interest, will remain outside our area of study. And likewise for those that have been solely executed over just one building wall. The works analysed here are based on the surface of several elements that shape the public space, usually in the city.

The procedure of applying colour to architecture -either through pigmentation or through the materials used- is nothing new; there are a large number of architects that use colour in their projects in a deliberate way, such as Sauerbruch \& Hutton, EMBT architects, Herzog \& De Meuron, William Alsop, Jean Nouvel, or MVRDV studio. And much earlier than them Theo van Doesburg, Le Corbusier, Bruno Taut or Gerrit Rietveld, among others, regarded colour as an essential element of their designs. What is not that common in the realm of architecture is the addition of colour after finishing the building. This modus operandi seems more typical of artists that work solo and who add colour -despite the fact that a number of them have some architectural education- in a freer and more personal fashion, to the extent of even thoroughly hiding the formal characteristics of the buildings that act as support. It is not common either that when conceiving the outer chromatic design of a building architects assess the possibilities of adding colour as out of bounds for the strict confines of the edifice; unlike the artists subject to the analysis of this paper, who re-signify not only the building and its surroundings, but also the chromatic strategies followed in the construction's initial design. With regards to the former, Juan Serra establishes three possibilities: "[The use of] colour to interfere with the visual perception of the form (its geometry, dimensions, visual weight, or texture); colour to interfere with the description of the architectural object (its composition as well as its function); and colour because of its inherent chromatic value". ${ }^{3}$

All through this paper, we will review the following four proposals: Krijn de Koning's The Museum of Gravity (2009), Jessica Stockholder's Color Jam (2012), Katharina Grosse's Rockaway! (2016), and Heather Day's intervention for the firm Flax Art \& Design (2016). The selection is shaped thusly because of their sharing not only the features described in the paragraphs above, but also the following: there is a flat application of colour in all of them, no matter painting or relief whatsoever, a feature even present in the interventions which get a gestural or organic finish (the latter two). Each of them answers to a different pictorial style, and focus the in situ intervention on the public space differently, contributing diverse perspectives on the phenomenon. Besides, though none among the four has been conceived from the standpoint of tactical urbanism (that was not their creators' intent at least), ${ }^{4}$ they show some features that get them quite close to this trend in different ways and with varying degrees of intensity. Lastly, all the interventions subject to study stand out because of their high aesthetical value, yet never reaching a rather trivial and garish decorativism (something that is not free from heated arguments when it happens to heritage buildings) which has been present in a number of pictorial actions carried out in urban spaces in the last few years. These last two issues will be argued at length in the section "Discussion and Conclusions".

p.73 KRIJN DE KONING: THE MUSEUM OF GRAVITY (2009)

Krijn de Koning's (Amsterdam, 1963) work fall in the boundary between art and architecture because of his erecting large structures, made with wood and plaster, which he subsequently paints with a gleaming and homogeneous coat of colour. Those seem like tiny living quarters with a minimalist look, which go inside older buildings or dwell on the 
outside, floors, walls, and staircases; all of which may be a direct consequence of his twofold education, in visual arts as well as in architecture..$^{5}$ Therefore, he creates structures within others already standing, adding a new temporal layer, so that visitors experience the place as if it were new.

A typical feature in De Koning's modus operandi is that he enmeshes his work both in old and contemporary buildings, but preserving at all times the original location and always with a commitment to reversibility, thanks to the materials used and to not applying paint directly over the building, but over his modular structures. However, space and form are not the only important elements for the artist: the colours are as significant as the structure in his projects.

With his installations, De Koning provides us with sensory experience of space and suggests a new relationship between human being and the constructed space. In The Museum of Gravity (2009) [see figures 1, 2, and 3], ${ }^{6}$ his distinctive colour structures are respectfully placed on and around the ruins of Ten Duinen abbey (Koksijde, Belgium), thus showing new ways of using and interpreting a location. ${ }^{7}$ The many chromatic contrasts that appear in the panels shaping the artist's installation -light/dark, warm/cool, complementary and qualitative- ${ }^{8}$ offer a contrast with the greys and ochres with which the patina of time has covered the stone used to build that Cistercian monastery. We can see that the application of colour in this project agrees with strategies 1 and 3, as defined by Juan Serra, ${ }^{9}$ but also the second, given that colours are adapted to the shape of the wooden structures built by the artist, though not to the abbey's architecture.

We can also perceive a stark contrast between the materials: the smooth and flat-coloured coating in De Koning's structures against the roughness and heterogeneity in the building's masonry. ${ }^{10}$ With regards to the abbey, we must underline that not everything is part of the original work since a great part of the standing remains has been recently rebuilt. This fact caught De Koning's attention and spurred him to reproduce the alleged "reality" of the ruins with his work so that his redundant gesture or hyperbole of artificiality should reveal the archaeological fallacy of the place. In the artist's words, his colourful structures "pretended to be 'real' architecture, in a situation of a 'real', lasting and 'serious' architecture that pretended to be 'fading' and declining". ${ }^{11}$ By showing this double lie to the visitors -his fictive architectures on one hand, and the prefab stonewalls on the other-, he succeeds at provoking unease and amazement, as well as propitiating a questioning of "[the] significance and 'truth' of the place as it was constructed and represented in reality". ${ }^{12}$

The Museum of Gravity took part in the Beaufort 03 Art Triennale, which included around thirty site specific projects in the Belgian seaside from March to October 2009; they set up a dialogue with the sea, the cultural and patrimonial heritage, the locals and the history of the area. ${ }^{13}$ The usual visitors of the abbey and the medieval museum next to it grew thanks to the people attracted by De Koning's work, and this is why -in his view- the place was given greater attention when people wondered "what and why that work was there". ${ }^{14}$ Furthermore, according to the artist, most of them "simply enjoyed the work as some sort of strange scenery in that situation". ${ }^{15}$

\section{JESSICA STOCKHOLDER: COLOR JAM (2012)}

The work of the artist Jessica Stockholder (Seattle, 1959), also a professor of Visual Arts at the University of Chicago, is characteristically produced by means of an assemblage of objects in different shapes and materials, with which she acts on the location a number of times by generating a dialogue with architecture in site specific projects. She has produced pieces in a smaller size, but also monumental works that stem -according to Jorge Kunitz- "from her eagerness to be aware of the spaces in which she is working and to adhere to them by means of the materials she uses". 16

Though some authors place her in the realm of sculpture, the prominence she gives to colour in her installations supports that her projects should qualify as expanded painting, which makes them particularly interesting for our research. The artist adds in that regard: "My works can be understood as 'paintings in a space'. I enjoy very much arranging the collision of a static experience of painting against the temporal experience of moving through space". ${ }^{17}$

She works with an extended and wide-ranging palette of high-contrast colours, be it by brightness, saturation, temperature, or complementariness ${ }^{18}$ characteristics that belong to the objects she uses or something extra added by means of pictorial matter, "with which she amalgamates the different elements that shape the piece". ${ }^{19}$

There are not many projects developed by the artist outdoors, one of the few being Color Jam (2012) -see figures 4, 5, and 6-, ${ }^{20}$ a temporary installation (from June to September) that was part of the programme of cultural activities, dance, and music developed by the commercial and cultural organisation Chicago Loop Alliance. ${ }^{21}$ In this case, the artist does not use objects to intervene upon the selected location, the intersection of State and Adams Street, but coats of colour made of adhesive vinyl and vinyl mesh, which she stuck to the street surface, urban furniture, and adjacent buildings. As it can be seen in figure 4, "the volume of color intersecting the intersection was accommodating to the city's grid structure and, at the same time, at odds with it", ${ }^{22}$ given that the artist underscores by applying colour 
the four pedestrian crossings of the intersection and adjoining pavements, but she also places diagonally the other chromatic planes that aim to reject the reticular plan of the urban planning in the intervened-upon area.

This time, the palette employed by the artist is more reduced than in other projects; just red, green, and blue.

p.77 The colours are applied by means of flat shades, without gradation, and perfectly delimited by the geometrical shapes containing them. Colours cover the surfaces as if it were a second skin, adapting to any volume or irregularity. Moreover, the hues applied contrast strongly against the grey of the street tarmac and the intervened-upon buildings, adding brightness and a somewhat playful nature to the area, promoting interactions between the locale and pedestrians, who thanks to Stockholder's intervention become aware of the place and experience it in a more intense and meaningful way. Likewise, we should mention that Chicago Loop Alliance's goal when sponsoring Color Jam was to activate the city's downtown by means of contemporary art; therefore, while the intervention lasted, it functioned as a meeting point and to develop different activities, such as concerts or art workshops. In this work, colours interfere with the architectural characteristics, providing them with some singularity, and modifying the perception of their formal

p.78 elements; but they are also applied in certain areas with a functional intent, adapting it for instance to the boundaries of pedestrian crossings, as we have mentioned before. Similarly, they are used for purely artistic principles. Because of all that, in this piece we can conclude that applying colours to architecture and urban space fulfils the three chromatic strategies put forward by Juan Serra. ${ }^{23}$

\section{KATHARINA GROSSE: ROCKAWAY! (2016)}

Katharina Grosse (Freiburg, 1961) began painting at 20, after studying at Dusseldorf's Kunstakademie, but already as a child she paid attention to features like the shadows produced in and by architecture, which she fantasised about erasing with colours since, for the artist, to look at the world is linked to the fact of doing something on it and with it, in the view of Vanessa García-Osuna. ${ }^{24}$ As years go by, she transcends the physical limitations of the support in her works, as well as increasing their monumentality by means of colour, a key element for K. Grosse "because it triggers an immediate resonance in the viewer [...]. The choice of colour can highlight an area or an object in infinite ways. It can utterly shape our experience! [...]. Colour is the most magical element to transform surfaces that there is. It doesn't have to be somewhere precise. It can pop up anywhere". ${ }^{25}$

Among all her projects, we have chosen the intervention Rockaway! (2016) as a case study -see figures 7, 8,

p.80 9-26 which unlike the project analysed so far by De Koning and Stockholder was carried out in a natural yet partially urbanised environment: the beach in the Rockaway peninsula, located in Fort Tilden Natural Park (New York) and sharing whereabouts with an erstwhile base of the U.S. Army, which currently belongs to the Gateway National Recreation Area. The importance of this proposal resides in the way in which the artist applies colour to the buildings, an abandoned military precinct laid waste by hurricane Sandy in 2012. Grosse uses a high-pressure airless spray gun with a handle, from a crane on occasion so as to reach the higher parts of the building and the roof. The device works as an extension of her own arm, which results in a sort of faded dripping and open composition all over, eventually covering most of the interior and the exterior of the original building and part of the adjacent paving. ${ }^{27}$

Rockaway! was commissioned by MoMA PS1 in collaboration with other organisations, such as Jamaica BayRockaway Parks Conservancy or Rockaway Beach Surf Club, as part of a recovery programme after the sheer destruction provoked by hurricane Sandy in the peninsula. The artist works with the architecture of the chosen building from a purely formal approach, starting from the empty shell that remained after the cyclone passed by (figures 7 , 8, and 9). Grosse intervenes in a location laden with connotations, in which the walls seem to be oozing the tragic memory of the place. Doomed to demolition, thanks to the art intervention the building was given a new lease on life, however brief, and it works as a sort of homage before going into oblivion. When looking at the images of the artwork one feels that Grosse's goal is to erase the past of the building by means of several coats of paint in red shades, alternating with white. But it also seems to re-create the ocean waves, which appear to be enfolding or hitting the building, thus calling to mind the hurricane aftermath on its walls. ${ }^{28}$

With regards to the creative process, the artist's first action was to paint the building white and cover all the graffiti tags over the walls, both interior and exterior, thus hiding any previous chromatic occurrence. We should mention that no chromatic strategy is followed in the initial application of colour to the building, so Grosse's intervention does not involve any modification in that sense, but an add-on: the integration of colour as a new element that intervenes in the building's perception, but so prominent that it almost renders the remaining architectural elements null and void. Based on what has been previously stated, one could say that Grosse's intervention fits within Juan Serra's strategy $1,{ }^{29}$ in which colour interferes with the architectural properties and breaks them up, destroying their characteristic geometry, hampering the outward texture, and splitting up the components of the architectural form. Furthermore, it fulfils the third strategy given that it boosts the intrinsic value of colour.

\section{HEATHER DAY: INTERVENTION IN THE FIRM 'FLAX ART \& DESIGN' (2016)}

The American artist Heather Day (Hawaii, 1989) creates art within lyrical and gestural abstraction, in portable formats and supports as well as over both interior and exterior architectural surfaces. Her creative process is quite visceral and driven, which leads her to involve her entire body in the origin of every work -especially in the larger ones- in a sort of performance which echoes the action painting of American abstract expressionism.$^{30} \mathrm{In}$ her compositions, she uses a wide-ranging colour palette that stands out for its harmony and the presence of several types of contrast: warm-cool, 
brightness, qualitative, complementary colours, ${ }^{31}$ and such, depending on the case. Another feature of her work is that it can be understood from the viewpoint of synaesthesia, since it links some perception from one sense to the perceptions of another. ${ }^{32}$ From her projects, we have chosen as case study her first intervention in the public space, being as well the largest work the artist had produced up until then, in $2016 .{ }^{33}$ It was a project for the artistic materials company Flax Art \& Design, more specifically for their headquarters, located between $15^{\text {th }}$ Street and Martin Luther King Jr. Way, in downtown Oakland (California), with the collaboration of Athen B. Gallery. Since it was a milestone in her career, the artist went for innovation and rejected producing a mere mural; so she decided "to challenge the conventional and paint a new breed of mural; one that would start conversations and would raise questions about spatial relationships and architecture". ${ }^{34}$ To that aim, she intervened on the cladding of two walls that shaped a corner of the warehouse, as well as the adjoining pavement. Her intervention on the floor was not intended, but it simply had to happen when she saw the promise of some paint drops over it, according to the artist. ${ }^{35}$ Day took advantage of the chance event to provide her work with greater depth by amplifying its compositional planes, thus transcending the two-dimensional nature of a typical canvas.

The links between her project and its architectural and urban setting are strengthened by the inclusion in the piece of the surrounding textures: the cracks in the pavement, the grid of the brickwork in the intervened walls, as well as the shadows of the wires and phone posts that are projected on the building throughout the day, in dialogue ${ }^{36}$ with her graphic design (see figures 10,11, and 12). It is meaningful to see how the organic blots and the gestural lines devised by Day go against the orthogonal rigidity of the brickwork and other construction elements in the Flax warehouse, thus achieving compositional balance. On the other hand, and according to Carolyn Mendle-Smith, ${ }^{37}$ the rising trajectory in many lines and brushstrokes provoke the illusion that the building walls climb skyward, eventually merging with it; moreover, the paint blots over the pavement welcome pedestrians to come in and walk on the work. Because of all that, Day manages to amplify the architecture, to break with its rigidity by blurring its limits with her pictorial work and, thus, turning the city into a friendlier place, ultimate goal of the artist. To achieve that aim, the artist suggests: "The rough textures and high walls in cities often have negative connotations - they can make us feel unwelcome, or like we are being contained or perhaps even kept out. I wondered if architecture was just something we have to accept within a city, or if there were ways we can challenge it. How can we open up our city walls?" 38 To contribute with her work to the making of a healthier urban environment, while the process of the work execution lasts, she deems the conversation with the neighbours unavoidable, so as to involve them in its development. The community's view is of the essence to complete the work; in fact, the value they add belongs particularly to this contribution, according to Day as well: "[...] in the conversations we begin, the connections we create, and the legacy of relationships we foster along the way". ${ }^{39}$

As regards the chromatic range used, reddish (magenta, red, and orange) and blue shades (Prussian, cobalt, and manganese) predominate, together with grey, contrasting in brightness and temperature among them but also against the basic white background of the building, over which they are organised but without covering completely. Therefore, the work begins in a chromatically neutral architectural setting, in which colour has been applied without any defined goal, so it is by virtue of Day's painterly work that it acquires compositional relevance. According to the chromatic strategies reviewed, the artist's approach would agree with Juan Serra's ${ }^{40}$ strategy 1 because of colour interfering with the visual features of the architecture, assimilating it to the environment and fostering "unique conversations and interactions with the surrounding space, shadows, passers-by, and the bright blue Oakland sky"; 41 but also with the third strategy, since the visual strength shown by the very blots and gestures of the artist is undeniable.

\section{DISCUSSION AND CONCLUSSIONS}

Tactical urbanism has been defined by authors like Mike Lydon, ${ }^{42}$ Marisol García and Javier Vergara, ${ }^{43}$ or Antonio R. Montesinos ${ }^{44}$ as those actions aimed at transforming the cities to improve life within them, actions that promote citizens' pro-activism when facing current urban problems and that are supported by neighbourhood associations and local organisations, as well as public and private institutions by means of a collaborative process. It involves creative solutions (authorised or not) carried out with little resources, a flexible development, small scale, local setting, temporary nature, realist expectations and, in case they work, which may evolve into thoroughly planned actions in a larger scale, and permanence in time. Analysed from this perspective, the four pictorial interventions reviewed in this paper share some of the features mentioned, though not all, including them in their development in a rather specific way depending on the case, as we will expound anon.

The Museum of Gravity does not have a clear "tactical" purpose, except raising awareness of the historical heritage and question its alleged veracity, contributing at the same time to the economic activation of the area by bringing visitors to the abbey and its museum. After its selection by the Beaufort 03 Art Triennale, we may consider that the artwork is the result of the collaboration between the artist and different institutions involved in the organisation, though authorship remains exclusively De Koning's. It shows other features as well, such as the limited period of time, a not too terribly steep expenditure, and a reasonable size; all of which seem to align this project with the tenets of tactical urbanism.

Color Jam: this intervention was commissioned by a neighbourhood association with the aim of galvanising their district as regards commerce and culture. In order to be developed, it was necessary to get the approval of the proprietors, whose houses and business premises would be affected by the work, though they did not participate in its planning, a role taken up by Stockholder alone, as she informed us via personal communication. ${ }^{45}$ The artist has also declared that 
her aim when intervening over the pedestrian crossings was not to boost their visibility, keeping her distance then from the tactic of "fixing intersections" as stated by Mike Lydon. ${ }^{46}$ However, the fact that the work served as meeting point and location for the development of different activities provides it with a function, unforeseen by the artist: recovering the street as the realm of public meetings, a feature included in the aforementioned tactic, just as its temporary nature.

Rockaway!: the same as the previous two, this project was sponsored by a number of public and private institutions, in this case to celebrate the upturn of Rockaway Peninsula after hurricane Sandy had wreaked havoc on it. Thus, we can say that the work happened because of a manifold collaboration, though the sponsors did not get involved in its formal and conceptual development at all. It is a temporary project focused on a building that would be demolished, just as were many others scattered through the area; this was to erase the remnants of time marked by the military use of the land to enter a time characterised by its being declared a natural park and enjoyed by the civilians. On this matter, the work could be ascribed to tactical urbanism, although this approach may be far from Grosse's intentions.

The intervention at the Flax Art \& Design warehouse is the only work conceived with a permanent nature, but it is again the only one that took into account the views of the neighbours during its completion, which showed its creator as someone worried about how it would be received and perceived by the dwellers of the neighbourhood where it is located. By planning the work with the thought of acting upon architecture in order to develop friendlier cities, Day takes an unpremeditated stand within tactical urbanism, fulfilling as well other related features, such as flexibility (the work was being modified along its execution), a contained scale, low budget, or local setting.

Antonio R. Montesinos states that the actions included in tactical urbanism promote that "our cities should evolve into more aesthetic and humane spaces". ${ }^{47} \mathrm{In}$ his view, ${ }^{48}$ these actions must find a balance between usability and design, given that the proposals with a more graphic or visual development provide citizens with a more satisfying experience. The value this author confers to aesthetics brings the four pictorial interventions closer to this phenomenon, since the formal aspects are well cared-for in all, and for good reason: all were created by artists. To the aesthetic function we should add the one of signposting a given building or urban area, as well as others that have been individually examined when analysing each particular project. Hence, we have to understand them as works far away from any interpretation within pure decorativism, since even their application of colour relates to precise strategies, linked to the architectural background against which they are developed or to sheer meta-pictorial criteria, but they do not threaten the intervened building in any way -not even when they are listed heritage-, whether it be on account of their ephemeral or reversible nature -the case of The Museum of Gravity or Color Jam-, because of acting upon a building to be demolished -as in Rockaway!-, or for the reason that it integrates the elements and textures of the building and adjacent areas into the very work - as it happens in Heather Day's intervention. Therefore, the four projects subject to study steer clear of the current debate about cases such as 'Miguel Fisac Sports Complex' (Getafe, Madrid) or the lighthouse at Cape de Ajo (Cantabria), whose material, aesthetic, and stylistic characteristics have been altered by the pictorial interventions of Boa Mistura Collective and Okuda San Miguel, respectively. Some authors have considered those instances as clear contempt for the historical value of the original buildings.

Finally, we should mention that all the interventions subject to analysis are located in standing constructions whose colour was neutral (grey, ochres, or white), originated by the very building materials, or by painting added later in the case of the Flax Art \& Design warehouse. Therefore, the original architectural design does not follow any of the chromatic strategies theorised by Juan Serra, but it is the later pictorial intervention what makes such a reading possible. Of the three chromatic mechanisms highlighted by this author, we can see that the proposals by Krijn de Koning and Jessica Stockholder fulfil all three, whereas Katherina Grosse's and Heather Day's only connect with two, the first and the third. This fact leads one to think about a possible relationship between the type of abstraction to which the pictorial intervention may be ascribed, and the application of some chromatic strategies or others. On the other hand, in the four cases studied here, colours confer singularity to the building or urban area on which they are applied, standing out from the rest of the surrounding architecture. This feature opposes the one about a building's mimesis with the landscape, which can also be achieved through the application of colour, according to Serra, ${ }^{49}$ but that is not the case of the works subject to study. $\square$

This paper gathers the results of the R+D+i research project "El barrio como scenario de pedagogías críticas y arte colaborativo [The Neighbourhood as Setting for Critical Pedagogies and Collaborative Art PGC2018-094351-B-C42)", financed by Programa Estatal de Generación de Conocimiento y Fortalecimiento Científico y Tecnológico of the Ministry of Science, Innovation, and Universities.

Each author contributed to this paper as follows:

Aurora Alcaide-Ramírez: Conceptualisation, data curating, revision and editing of the final text.

Ana Ruiz-Abellón: Bibliographic research, image selection and edition, management of rights for their publication.

Both: development of the research, methodological design, and composition of the paper.

1. Among many others, we refer to the following authors: GARÍ, Joan. La conversación mural. Ensayo para una lectura del graffiti. Madrid: Fundesco, 1995; PEIRÓ LÓPEZ, Juan Bautista (2010). El muro como soporte en la pintura contemporánea: anotaciones marginales. In: Arte público hoy: nuevas vías de consideración e interpretación crítica. Actas del Congreso Internacional de Críticos de Arte. España: ACYLCA y AECA, 2009, pages 159-167; FERNÁNDEZ FARIÑA, Almudena. Pintura site. Santiago de Compostela: Dardo, 2014; MADERUELO, Javier. La idea de espacio en el arte y la arquitectura contemporáneos 1960-1989. Madrid: Akal, 2008; ARDENNE, Paul. Arte contextual. Creación artística en medio urbano, en situación, de intervención, de participación. Murcia: CENDEAC, 2006; FERNÁNDEZ FARIÑA, Almudena. Lo que la pintura no es. La lógica de la negación como afirmación del campo expandido en la pintura. Pontevedra: Diputación de Pontevedra, 2009.

2. In the first issue of the magazine Internationale Situationiste psychogeography is defined as "the study of the precise laws and specific effects of the geographical environment, consciously organised or not, on the emotions and behaviour of individuals." See FERNÁNDEZ CONSUEGRA, Celia Balbina. Internacional Situacionista, movimiento 
precursor del performance art. In: Revista index.comunicación [online]. Madrid: Universidad Rey Juan Carlos, 2014, vol. 4, nº 1, page 135 [last access: 10-09-2020]. E-ISSN 2174-1859. Available at: https://journals.sfu.ca/indexcomunicacion/index.php/indexcomunicacion/article/view/128/146.

3. SERRA LLUCH, Juan. La versatilidad del color en la composición de la arquitectura contemporánea europea: contexto artístico, estrategias plásticas e intenciones [online]. Thesis advisor: Ángela García Codoñer. Doctoral disertation. Universidad Politécnica de Valencia, Departamento de Expresión Gráfica Arquitectónica. TESE0, 2010 [last access: 03-09-2020]. Available at: https://www.educacion.gob.es/teseo/imprimirFicheroTesis.do?idFichero=\%2FappnNbNLRQ\%3D, page 7.

4. A purpose that can indeed be seen in the supporters of some works, like Rockaway! and Color Jam, as it will be seen in the section "Discussion and Conclusions". 5. SLEWE GALLERIE. Krijn de Koning - Bio [online]. Amsterdam, undated [last accessed: 09/04/2020]. Available at: https://www.slewe.nl/artists/krijndekoning. 6. Full-colour images of said figures can be seen in Designboom magazine. Available at: https://www.designboom.com/architecture/krijn-de-koning-the-museum-of-gravity/.

7. KONING, Krijn de. Texts, Interviews, Articles, Krijn de Koning - Works. Undated [accessed: 09/10/2020]. Available at: https://www.krijndekoning.nl/texts/index.html. 8. ITTEN, Johannes. The Art of Color: the subjective experience and objective rationale of color. New York: Van Nostrand Reinhold, 1973. The original edition was published in 1961. 9. SERRA LLUCH, op. cit. supra, footnote 3 .

10. ARCHER, Nate. "Krijn de Koning: The Museum of Gravity". Designboom magazine [online]. Milan, Italy, October 6, 2009. [Last access: 09/03/2020]. Available at: https:// www.designboom.com/architecture/krijn-de-koning-the-museum-of-gravity/.

11. Conversation with Krijn de Koning, February 1st, 2021.

12. Idem.

13. Beaufort Triennale. Artmap. Undated [last access: 02/03/2021]. Available at: https://artmap.com/beauforttriennale/exhibition/beaufort03-2009-2009?print=do.

14. Conversation with the artist. See footnote 11.

15. Idem.

16. KUNITZ, Jorge. "Jessica Stockholder: "El color es el alma de mi trabajo”". Tendencias del Mercado del Arte [online]. January 2012 [last access: 09/11/2020]. Available at: http://www.tendenciasdelarte.com/jessica-stockholder-enero-2012/.

17. Ibid.

18. ITTEN, op. cit. supra, footnote 8.

19. KUNITZ, op. cit. supra, footnote 16

20. Full-colour images can be seen in Jessica Stockholder's website: https://jessicastockholder.info/projects/art/color-jam/.

21. BLAIR, Gwenda. "At a Busy Intersection, Going Beyond Red, Yellow and Green". The New York Times [online]. Nueva York, June 5, 2012 [last access: 09/12/2020]. Available at: https://www.nytimes.com/2012/06/06/arts/design/color-jam-by-jessica-stockholder- opens-in-chicago.html.

22. STOCKHOLDER, Jessica. Color Jam [online]. Jessica Stockholder website. Undated [last access: 09/06/2020]. Available at: https://jessicastockholder.info/projects/art/ color-jam/.

23. SERRA LLUCH, op. cit. supra, footnote 3.

24. GARCÍA-OSUNA, Vanessa. "Katharina Grosse, la pintora sin límites”. Tendencias del Mercado del Arte [online]. February 2019 [access: 09/12/2020]. Available at: http:// www.tendenciasdelarte.com/katharina-grosse-febrero-2019/

25. Ibid.

26. Full-colour images can be seen at Katharina Grosse's website: https://www.katharinagrosse.com/works/2016 4003.

27. MUSEUM OF MODERN ART (MoMA). Katharina Grosse: Rockaway! | ARTIST STORIES [online]. New York, 2016 [access: 09/07/2020]. Available at: https://www.youtube. com/watch?v=chhyDJnhlew.

28. CASCONE, Sarah. "Katharina Grosse Paints the Rockaways Red for the Summer". Artnet.news [online]. July 3 ${ }^{\text {rd }}, 2016$ [access: 09/07/2020]. Available at: https://news. artnet.com/exhibitions/moma-ps1-katharina-grosse-rockaway-537179

29. SERRA LLUCH, op. cit. supra, footnote 3.

30. DAY, Heather. Studio Visit with Heather Day [online video]. YouTube. 2020 [access: 09/20/2020]. Available at: https://youtu.be/93V-NwGbL2E.

31. ITTEN, op. cit. supra, footnote 8.

32. DAY, Heather. About [online]. Heather Day website. Undated [access: 09/09/2020]. Available at: https://heatherday.com/about-cv.

33. DAY, Heather. Walls to Paint Open: Painting the Mural in Downtown Oakland [online]. Blogger. August 22, 2016 [access: 09/06/2020]. Available at: https://heatherday. com/notes/2016/8/19/walls-to-paint-open

34. Ibid.

35. Ibid.

36. Ibid.

37. MENDLE-SMITH, Carolyn. Live Art with Heather Day [online]. Flax Art \& Design blog. August 16, 2016 [access: 09/12/2020]. Available at: https://flaxart.com/flax-canvas/ live-art-with-heather-day/

38. DAY, Heather, op. cit. supra, footnote 33

39. Idem.

40. SERRA LLUCH, op. cit. supra, footnote 3.

41. MENDLE-SMITH, op. cit. supra, footnote 37.

42. LYDON, Mike. Urbanismo Táctico 2. Acción a corto plazo // cambio a largo plazo [online]. Translated to Spanish by A. KOGAN, K. STEFFENS, y J. VERGARA. Miami-New York: Street Plans, 2012 [access: 02/03/2021]. Available at: https://issuu.com/streetplanscollaborative/docs/urbanismo_tactico_2_digital_edition.

43. GARCÍA, Marisol; VERGARA, Javier. Urbanismo Táctico 3. Casos Latinoamericanos [online]. New York-Miami: Street Plans; Chile: Fundación Ciudad Emergente, 2013 [access: 02/04/2021]. Available at: https://issuu.com/eduartpit/docs/174221684-urbanismo-tactico-casos-l.

44. MONTESINOS, Antonio R. Urbanismo táctico. Arquitasa [online]. July 15, 2020 [access: 02/02/2021]. Available at: https://arquitasa.com/urbanismo-tactico/.

45. Conversation with the artist, taking place on February $1^{\text {st }}, 2021$.

46. LYDON, op. cit. supra, footnote 42.

47. MONTESINOS, op. cit. supra, footnote 44

48. MONTESINOS, Antonio R. Urbanismo táctico 2. Arquitasa [online]. August 19, 2020 [access: 02/02/2021]. Available at: https://arquitasa.com/arqticulos/urbanismo-tactico-2/.

49. SERRA LLUCH, Juan. Color for Architects. San Francisco: Chronicle Books, 2019. 

CITY. Darío Álvarez Álvarez • LINAZASORO EN REIMS. EL ESPACIO PÚBLICO COMO MEMORIA DEL LUGAR / LINAZASORO IN REIMS. THE PUBLIC SPACE AS THE MEMORY OF THE PLACE. Victoriano Sainz Gutiérrez • EDITAR VS. CONSTRUIR: UNA ECOLOGÍA DE LO INVISIBLE. AMPLIFICAR LA COMPRENSIÓN DE LAS TÉCNICAS DE PROYECTO / EDITING VS. BUILDING: AN ECOLOGY OF THE INVISIBLE. AMPLIFYING THE UNDERSTANDING OF ARCHITECTURAL DESIGN TECHNIQUES. Paula Victoria Álvarez Benítez • CUANDO LA PINTURA AMPLÍA LA ARQUITECTURA: INTERVENCIONES REALIZADAS EN EL ESPACIO PÚBLICO / WHEN PAINTING ENHANCES ARCHITECTURE: INTERVENTIONS IN A PUBLIC SETTING. Aurora Alcaide-Ramírez; Ana Ruiz-Abellón • UN EDIFICIO INVISIBLE. NUEVO AULARIO DE LA FACULTAD DE DERECHO DE LA UNIVERSIDAD DE ZARAGOZA (1983-1996) / AN INVISIBLE BUILDING. NEW LECTURE ROOM BUILDING OF THE FACULTY OF LAW OF THE UNIVERSITY OF ZARAGOZA (1983-1996). Luis Miguel Lus-Arana; Lucía Carmen Pérez-Moreno • ARQUITECTURAS AMPLIADAS. EL PABELLÓN DE EXPOSICIONES EN LA CASA DE CAMPO DE MADRID) / EXPANDED ARCHITECTURES. THE EXHIBITION PAVILION AT THE CASA DE CAMPO IN MADRID. José de Coca Leicher $\bullet$

- RAFAEL MONEO VALLÉS: LA VIDA DE LOS EDIFICIOS. LA MEZQUITA DE CÓRDOBA, LA LONJA DE SEVILLA Y UN CARMEN EN GRANADA . Víctor Pérez Escolano • FRANCISCO DE GRACIA: CONSTRUIR EN LO CONSTRUIDO. LA ARQUITECTURA COMO MODIFICACIÓN. Pablo Diañez Rubio • FRÉDÉRIC DRUOT, ANNE LACATON \& JEAN-PHILIPPE VASSAL PLUS: LA VIVIENDA COLECTIVA. TERRITORIO DE EXCEPCIÓN. Javier Terrados Cepeda.
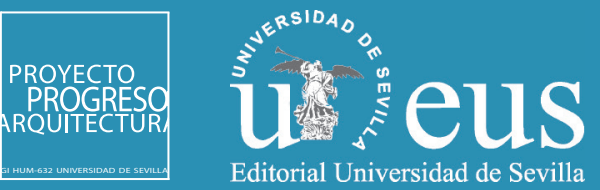